\title{
Complex refractive indices in the ultraviolet and visible spectral region for highly absorbing non-spherical biomass burning aerosol
}

\author{
Caroline C. Womack ${ }^{1,2}$, Katherine M. Manfred ${ }^{1,2, a}$, Nicholas L. Wagner ${ }^{1,2, b}$, Gabriela Adler ${ }^{1,2, c}$, \\ Alessandro Franchin ${ }^{1,2, \mathrm{~d}}$, Kara D. Lamb ${ }^{1,2, \mathrm{e}}$, Ann M. Middlebrook ${ }^{2}$, Joshua P. Schwarz ${ }^{2}$, Charles A. Brock ${ }^{2}$, \\ Steven S. Brown ${ }^{2,3}$, and Rebecca A. Washenfelder ${ }^{2}$ \\ ${ }^{1}$ Cooperative Institute for Research in Environmental Sciences, University of Colorado, Boulder, CO 80309, USA \\ ${ }^{2}$ Chemical Sciences Laboratory, National Oceanic and Atmospheric Administration, Boulder, CO 80305, USA \\ ${ }^{3}$ Department of Chemistry, University of Colorado, Boulder, CO 80309, USA \\ ${ }^{a}$ now at: Wolfson Atmospheric Chemistry Laboratories, Department of Chemistry, University of York, York, UK \\ bnow at: Ball Aerospace, Broomfield, CO 80021, USA \\ ${ }^{\mathrm{c}}$ now at: Breezometer, Haifa, Israel \\ ${ }^{d}$ now at: the National Center for Atmospheric Research, Boulder, CO 80305, USA \\ ${ }^{e}$ now at: Department of Earth and Environmental Engineering, Columbia University, New York, NY 10027, USA
}

Correspondence: Caroline C. Womack (caroline.womack@ noaa.gov)

Received: 20 November 2020 - Discussion started: 24 November 2020

Revised: 1 April 2021 - Accepted: 6 April 2021 - Published: 12 May 2021

\begin{abstract}
Biomass burning aerosol is a major source of $\mathrm{PM}_{2.5}$, and significantly affects Earth's radiative budget. The magnitude of its radiative effect is poorly quantified due to uncertainty in the optical properties of aerosol formed from biomass burning. Using a broadband cavity-enhanced spectrometer with a recently increased spectral range (360$720 \mathrm{~nm}$ ) coupled to a size-selecting aerosol inlet, we retrieve complex refractive indices of aerosol throughout the near-ultraviolet and visible spectral region. We demonstrate refractive index retrievals for two standard aerosol samples: polystyrene latex spheres and ammonium sulfate. We then retrieve refractive indices for biomass burning aerosol from 13 controlled fires during the 2016 Missoula Fire Science Laboratory Study. We demonstrate that the technique is highly sensitive to the accuracy of the aerosol size distribution method and find that while we can constrain the optical properties of brown carbon aerosol for many fires, fresh smoke dominated by fractal-like black carbon aerosol presents unique challenges and is not well-represented by Mie theory. For the 13 fires, we show that the accuracy of Mie theory retrievals decreases as the fraction of black carbon mass increases. At $475 \mathrm{~nm}$, the average refractive index is $1.635( \pm 0.056)+0.06( \pm 0.12) i$, and at $365 \mathrm{~nm}$, the average refractive index is $1.605( \pm 0.041)+0.038( \pm 0.074) i$.
\end{abstract}

\section{Introduction}

Biomass burning is one of the largest global contributors to accumulation-mode aerosol mass, with estimated emissions of $15-57 \mathrm{Tg} \mathrm{yr}^{-1}$ (Pan et al., 2020). In the United States, biomass burning is calculated to contribute $2.4 \mathrm{Tg} \mathrm{yr}^{-1}$ of $\mathrm{PM}_{2.5}$ aerosol, which accounts for one-third of the primary aerosol sources (Watson, 2002; Wiedinmyer et al., 2006). In the western US, increased wildfire frequency, wildfire duration, and active fire season have been associated with increased spring and summer temperatures (Westerling et al., 2006; Dennison et al., 2014). Biomass burning aerosol plays an important role in Earth's radiative budget by absorbing and scattering light (Boucher et al., 2013). Biomass burning smoke contains a complex mixture of particles with varying composition, morphology, size, and refractive index. The two major absorbing components are fractal-like graphitic material (black carbon; BC) and light-absorbing spherical organic aerosol (brown carbon; $\mathrm{BrC}$ ), with smaller contributions from dust (Li et al., 2003; Pósfai et al., 2003; China et al., 2013). One recent study estimated that biomass burning contributes $27 \%$ of black carbon emissions and $62 \%$ of primary organic aerosol globally (Wiedinmyer et al., 2011). 
The interaction of an aerosol particle with light can be calculated from its size, morphology, mixing state, and complex refractive index (RI). The RI is an intrinsic physical property of the particle and is described as $m=n+k i$ (Moosmüller et al., 2009; Moise et al., 2015). Light scattering by spherical particles is well described by Mie theory, which is a set of solutions to Maxwell's equations representing the scattering of light by a homogeneous sphere with dimensions similar to the wavelength of the radiation (Moosmüller and Arnott, 2009; Moosmüller et al., 2009). Many global models and satellite retrieval algorithms assume atmospheric aerosol particles are predominately spherical and calculate total aerosol extinction using Mie theory with a small set of constant RIs for different aerosol types (Liao et al., 2003; Levy et al., 2007; Omar et al., 2009; Lamarque et al., 2012). These RIs are often determined experimentally at a few wavelengths (Nakayama et al., 2010; Zhang et al., 2016) and extrapolated to the full solar spectrum.

Simple assumptions of sphericity and wavelengthindependent RI are not accurate for biomass burning particles, which consist of $\mathrm{BC}$ with complex morphology (Bond et al., 2013) and BrC with wavelength-dependent RIs (Washenfelder et al., 2013; Flores et al., 2014b; Laskin et al., 2015; Bluvshtein et al., 2017). The fractal-like agglomerates of highly absorbing black carbon are known to be poorly represented as spheres (Forrest and Witten, 1979) and are better described by more complex optical equations, such as Rayleigh-Debye-Gans (Sorensen, 2001; Manfred et al., 2018). Accurate measurements of the size distributions, morphology, and wavelength-dependent refractive indices of biomass burning aerosol are important to better model their climate forcing.

One technique to measure wavelength-dependent RIs is broadband cavity-enhanced spectroscopy (BBCES), which combines a broadband light source with highly reflective mirrors to measure total light extinction by particles or gas-phase species at multiple wavelengths simultaneously (Fiedler et al., 2003; Washenfelder et al., 2008; Varma et al., 2013; Zhao et al., 2017). The absorption and scattering of an aerosol population can be determined by making multiple size-selected measurements of extinction and using Mie theory to retrieve the RI (Washenfelder et al., 2013; Flores et al., 2014a; Zhao et al., 2017; He et al., 2018). This method has been used successfully for retrievals of RI in the near-ultraviolet at 360-420 nm using LEDs (Washenfelder et al., 2013; Flores et al., 2014a) and for spectral regions as broad as 380$650 \mathrm{~nm}$ using laser-driven arc lamps (He et al., 2018; Li et al., 2020). Complex RIs have been reported for standard aerosol samples, such as nigrosin and Suwannee River Fulvic Acid (Washenfelder et al., 2013; Zhao et al., 2017), and for aged organic aerosol (Flores et al., 2014a, b; He et al., 2018; Li et al., 2020). However, these measurements have all been conducted with spherical, homogeneous particles generated in laboratory or chamber experiments. This method has not been previously demonstrated for measurements of com- plex populations of non-spherical, highly absorbing black and brown carbon that are representative of biomass burning aerosol.

In this paper, we determined complex refractive indices for biomass burning aerosol across a very broadband region from $360-720 \mathrm{~nm}$. We measured wildfire smoke samples from representative fuels and burn conditions at the Missoula Fire Sciences Laboratory (Manfred et al., 2018; Selimovic et al., 2018). We used the broadband extinction measurements and two independent measurements of the aerosol size distribution together with a retrieval algorithm and several theoretical scattering models to determine complex refractive indices. We validate the retrieval algorithm with spherical, monodisperse populations of polystyrene latex spheres and polydisperse populations of ammonium sulfate. We analyze smoke from 13 fires at the Fire Sciences Laboratory, present detailed examples where the retrieval algorithm can and cannot be used to accurately characterize the complex refractive index, and discuss the implications for remote-sensing retrievals.

\section{Experimental}

\subsection{Overview of the Fire Sciences Laboratory 2016 study}

The Fire Influence on Regional and Global Environments Experiment (FIREX) 2016 study was conducted at the U.S. Forest Service's Missoula Fire Sciences Laboratory during October-November 2016 (Manfred et al., 2018; Selimovic et al., 2018). The Fire Science Laboratory contains $\mathrm{a} \sim 3400 \mathrm{~m}^{3}$ indoor combustion room for controlled burns (McMeeking et al., 2009; Selimovic et al., 2018). The measurements reported here are for "room" burns, where instruments sampled well-mixed smoke from the combustion room. First, dry fuels weighing $0.24-4.4 \mathrm{~kg}$ were placed on a ceramic fuel bed and ignited by a heating plate to produce a small, controlled burn that lasted several minutes (Selimovic et al., 2018). The smoke became well-mixed in the combustion room within 15-20 min and persisted under steadystate, low-light conditions for 3-4h with minimal dilution and wall loss (Stockwell et al., 2014). Fuels were representative of western US wildfires and included ponderosa pine (Pinus ponderosa), lodgepole pine (Pinus contorta), Douglas fir (Pseudotsuga menziesii), Engelmann spruce (Picea engelmannii), subalpine fir (Abies lasiocarpa), manzanita (Arctostaphylos), chamise (Adenostoma fasciculatum), juniper (Juniperus), and sage (Artemisia) (Selimovic et al., 2018). A shared aerosol inlet was connected to the combustion room, and it provided flow to a size-selected inlet and the BBCES instrument, as described below. 


\subsection{Broadband cavity-enhanced spectrometer for aerosol extinction at $360-720 \mathrm{~nm}$}

The optical system shown in Fig. 1a is a modified version of the two-channel instrument used previously to measure broadband aerosol extinction at 355-420 nm with two LEDs (Attwood et al., 2014; Washenfelder et al., 2015). The light source, optical filters, cavity mirrors, and spectrometer grating were replaced to measure aerosol extinction over a very broadband region, covering 360-385 and 400-720 nm.

We used a single laser-driven white-light source (EQ99FC LDLS; Energetiq, Woburn, MA, USA), containing a continuous-wave laser at $974 \mathrm{~nm}$ that pumps a Xenon plasma and outputs a broad spectrum from 170-2100 nm (Islam et al., 2013). The light source was temperature-controlled to $\sim 20^{\circ} \mathrm{C}$ and purged with $\mathrm{N}_{2}$ to eliminate $\mathrm{O}_{3}$ production (Washenfelder et al., 2016). The light was transmitted by fiber-optic to an off-axis parabola with a 0.36 numerical aperture (RC04SMA-F01; Thorlabs, Newton, MA, USA) for collimation and coupling into the optical cavities. Two colored glass filters (WG345 and WG320) were used to remove UV wavelengths shorter than $345 \mathrm{~nm}$. A dichroic longpass filter with a $400 \mathrm{~nm}$ cut point (69-897; Edmund Optics, Barrington, NJ, USA) divided the light before it was passively coupled to the two optical cavities. Additional colored glass filters and a custom interference filter (MLD Technologies LLC, Mountain View, CA, USA) eliminated out-of-band wavelengths.

The optical cavities consisted of two pairs of $2.5 \mathrm{~cm}$ diameter, $1 \mathrm{~m}$ radius of curvature plano-concave mirrors with a high-reflectivity coating covering 360-385 nm (Advanced Thin Films, Boulder, CO, USA) and 400-720 nm (MLD Technologies LLC, Mountain View, CA, USA). The broadband reflectivity of the visible mirrors was achieved with multiple layers of thin film coatings applied by ion beam sputtering to the super-polished substrate. Although the visible mirrors span a very broad range with high reflectivity (0.9993-0.9999), their losses vary strongly as a function of wavelength (Fig. S1) (He et al., 2018), due to the coating properties and possible contributions from surface roughness, interface roughness, and internal defects. The mirrors were mounted in stainless steel mounts, at either end of a $101.5 \mathrm{~cm}$ long aluminum flow cell $(2.21 \mathrm{~cm}$ i.d.) with inlets for the aerosol flow and mirror purge flows. The broadband light exiting each cavity was collected by an F/3.1 lens, coupled to a bifurcated fiber-optic bundle, and imaged linearly onto the entrance slit of a grating spectrometer (IsoPlane160; Princeton Instruments, Trenton, NJ, USA). The spectrometer contained a 300 grooves $\mathrm{mm}^{-1}$ grating with $300 \mathrm{~nm}$ blaze (centered at $507 \mathrm{~nm}$ with $290-724 \mathrm{~nm}$ bandwidth) and a 16-bit back-illuminated $2048 \times 512$ pixel charge-coupled device (CCD) detector (PIXIS 2kBUV; Princeton Instruments, Trenton, NJ, USA). During data acquisition, individual spectra were acquired with $0.3 \mathrm{~s}$ integration time using the physical shutter of the IsoPlane spectrometer. The CCD readout time was $0.57 \mathrm{~s}$, and so a full spectrum was taken every $0.87 \mathrm{~s}$. Narrow emission lines from a Hg lamp were measured multiple times each day to determine the wavelength calibration and spectral resolution (average full width at halfmaximum resolution of $1.4 \mathrm{~nm}$ between $360-720 \mathrm{~nm}$ ).

\subsection{Cavity ring-down spectrometer for aerosol extinction at $403 \mathrm{~nm}$}

A cavity ring-down spectrometer (CRDS) at $403 \mathrm{~nm}$ provided an extinction measurement between the two BBCES channels at 360-385 and 400-720 nm and was used as an independent validation of the BBCES extinction. The CRDS method has been described previously (Fuchs et al., 2009) and was not modified from Washenfelder et al. (2013).

\subsection{Automated flow system}

\subsubsection{Aerosol size selection and size characterization}

The custom automated inlet for aerosol size selection is shown in Fig. 1b. The materials and geometry of the flow system were chosen to maximize particle transmission and minimize inertial losses. The BBCES provides a direct measurement of wavelength-dependent aerosol extinction, but retrievals of complex RIs require extinction measurements of two or more size-selected aerosol populations with consistent composition (Washenfelder et al., 2013). Particle size selection was achieved with a custom-built differential mobility analyzer (DMA; now available from Brechtel Manufacturing Inc, Hayward, CA, USA (Knutson and Whitby, 1975)). In these experiments, the sample flow through the DMA was 0.5 or $1 \mathrm{vlpm}$ (volumetric $\mathrm{L} \mathrm{min}^{-1}$ ), with a sheath : sample flow ratio of $10: 1$ or $5: 1$.

As shown in Fig. 1b, the concentration and size distribution of the size-selected aerosol were determined using two separate methods. The first method was a condensation particle counter (CPC; 3022A, TSI Inc., Shoreview, MN, USA), which sampled at a flow rate of $0.3 \mathrm{vlpm}$ and measured the total number of particles with a lower aerosol size cutoff of $7 \mathrm{~nm}$. At regular intervals, the DMA and CPC were operated as a scanning mobility particle sizer (SMPS) to determine the aerosol size distribution by scanning the DMA column voltage up and then down between $0-5000 \mathrm{~V}$ over $240 \mathrm{~s}$ and applying an inversion algorithm (Twomey, 1975; Markowski, 1987). An instrument transfer function was then used to calculate the particle size distribution for each DMA set point. The inversion algorithm for the SMPS size distribution is most accurate for spherical aerosol with well-known mobility diameters. The second measurement of the particle size distribution was made using an optical particle counter. The optical particle counter (OPC) used here was a laser aerosol spectrometer (LAS 3340, TSI Inc., Shoreview, MN, USA), which detects light scattered by individual particles intercepting a $633 \mathrm{~nm}$ laser beam and reports the signal for each 


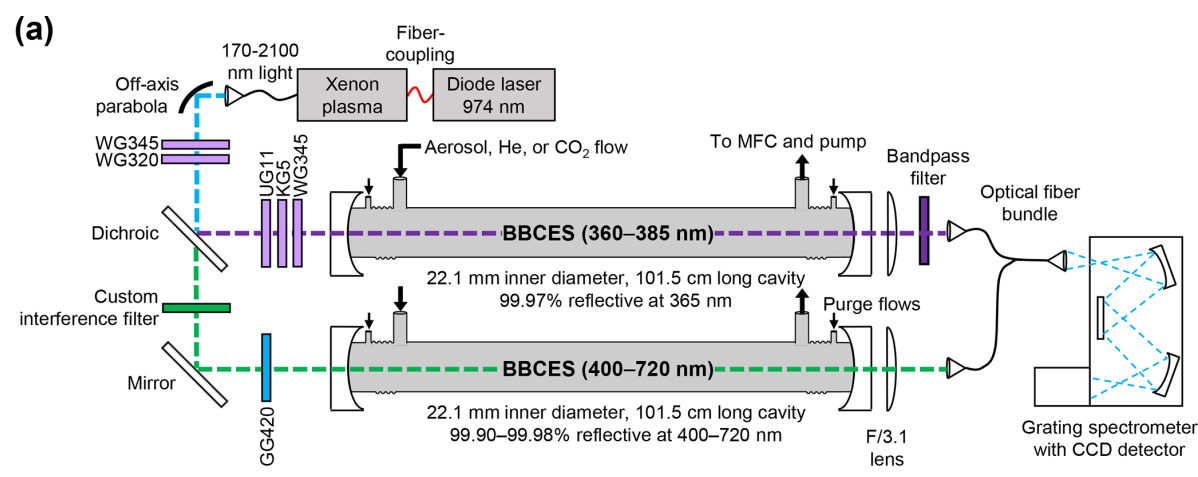

(b) BBCES Aerosol Inlet:

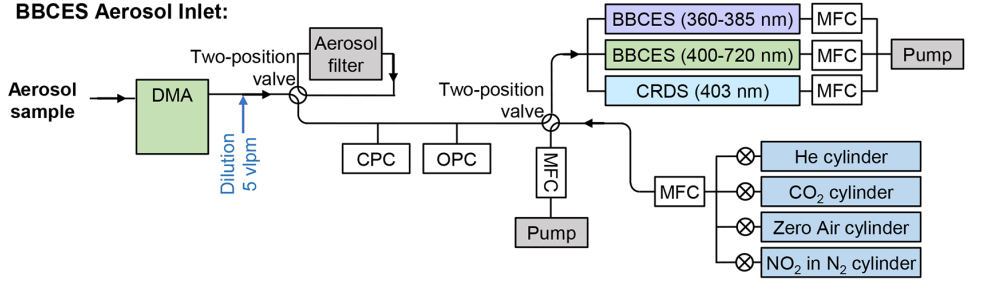

(c) NOAA Shared Aerosol Inlet:

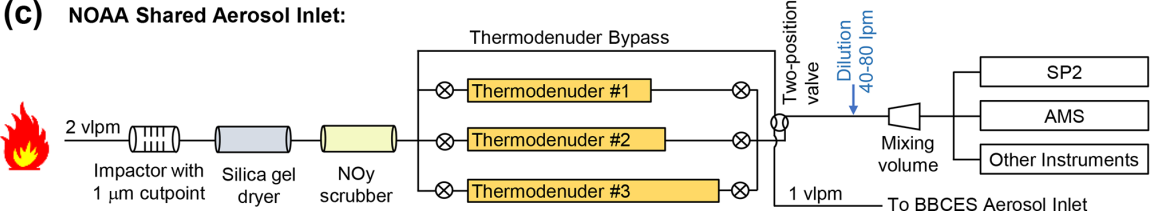

Figure 1. A schematic of the BBCES instrument and inlet at the Fire Sciences Laboratory. (a) The optical components of the BBCES instrument include a laser-driven arc lamp, off-axis parabola, colored glass filters, dichroic beam splitter, two BBCES cavities, and a grating spectrometer. (b) The automated flow system developed for the Fire Sciences Laboratory. Aerosol is size-selected by a DMA, with the number concentration continuously measured by a CPC and the size distribution periodically measured by an OPC. The flow is evenly divided between the two BBCES channels and the CRDS channel. An automated two-position valve allows flow to be directed through a filter to measure particle-free air, and a second two-position valve allows the introduction of calibration gases. (c) The common inlet shared by multiple aerosol instruments at the Fire Sciences Laboratory, including the SP2 and the AMS. Smoke was sampled at 2 vlpm through an impactor ( $1 \mu \mathrm{m}$ cut-point), silica gel dryer, and $\mathrm{NO}_{y}$ scrubber before traveling through a bypass channel or thermodenuder. A two-way valve alternately directed fresh and denuded aerosol to the BBCES and CRDS at 10 min intervals.

particle in 100 logarithmically spaced diameter bins. A total flow of 0.06 vlpm was used. During laboratory tests after the field campaign, we used a similar optical particle counter with a $1054 \mathrm{~nm}$ laser (UHSAS, Droplet Measurement Technologies, Longmont, CO, USA) because the LAS 3340 was not available. Optical particle counters are designed to measure scattering, and the mathematical interpretation of the signal for highly absorbing biomass burning aerosols is described in detail in Sect. 3.

\subsubsection{BBCES and CRDS flow system}

As shown in Fig. 1b, the size-selected aerosol flow was diluted with $5.0 \mathrm{slpm}$ (standard liters per minute) of dry, particle-free zero air after exiting the DMA. The resulting 6.0 slpm of diluted sample flow was directed to the BBCES and CRDS channels (2.0 slpm per channel). Each cavity was constructed of aluminum tubing $(22.1 \mathrm{~mm}$ i.d. for BBCES,
$7.7 \mathrm{~mm}$ i.d. for CRDS), and all tubing between the DMA and the optical cavities was made of stainless steel or flexible silicone tubing to minimize electrostatic particle losses. To protect mirror cleanliness, particle-free zero air flowed over each cavity mirror at a rate of $55-80 \mathrm{sccm}$.

Two automated two-position valves (MDM-060DT-3; Hanbay Inc, Pointe-Claire, Quebec, Canada) allowed additional calibrations and zeros. The first two-position valve rotated to direct the sample flow through an aerosol filter, providing an aerosol-free reference measurement for the BBCES and CRDS cavities. The second two-position valve allowed pure gases to be introduced for periodic measurements. As shown in Fig. 1b, gas cylinders of $\mathrm{He}, \mathrm{CO}_{2}$, zero air (Norco, Inc., Missoula, MT, USA), and $\mathrm{NO}_{2}$ in $\mathrm{N}_{2}$ (ScottMarrin, Inc., Riverside, CA, USA) were connected to automated valves and a mass flow controller (MFC). Pure $\mathrm{CO}_{2}$ and $\mathrm{He}$ were used to characterize the mirror reflectivity by filling the cavities and purge volumes with each gas for 1.5 
min at intervals of $\sim 1 \mathrm{~h}$. Pure zero air provided an aerosolfree extinction measurement, similar to the filter method described above. The cylinder containing $\sim 3 \mathrm{ppmv} \mathrm{NO}_{2}$ in $\mathrm{N}_{2}$ provided additions of $0-72 \mathrm{ppbv} \mathrm{NO}_{2}$ for flows of 0 $100 \mathrm{sccm}$. Due to known discrepancies between the reported and actual concentrations of $\mathrm{NO}_{2}$ calibration tanks (Chilton et al., 2005), this method was not used as a calibration but rather as an assessment of long-term stability of the instrument with respect to the $\mathrm{NO}_{2}$ spectral features. When the two-position valve was rotated for overflow of calibrant gas, the inlet sample flow and pressure were maintained using an MFC and pump to minimize disturbances to the DMA and other instruments.

\subsection{Shared aerosol inlet}

The flow to the BBCES and CRDS channels was provided by a shared aerosol inlet, shown in Fig. 1c. The shared aerosol inlet consisted of $\sim 30 \mathrm{~m}$ of $6.4 \mathrm{~mm}$ o.d. copper tubing connected to an inertial impactor with $50 \%$ cut point at an aerodynamic diameter of $1.0 \mu \mathrm{m}$ (TE296, Tisch Environmental, Cleves, $\mathrm{OH}$ ), a silica gel dryer, an activated carbon denuder to remove $\mathrm{NO}_{y}$ and $\mathrm{O}_{3}$ (Washenfelder et al., 2015), and three available thermodenuders. The 2.0 volumetric $\mathrm{L} \mathrm{min}^{-1}$ (vlpm) flow from the burn room was evenly split between one of the thermodenuders and a bypass channel. An automated two-position valve (Hanbay Inc, Pointe-Claire, Quebec, Canada) alternately directed $1.0 \mathrm{vlpm}$ of thermodenuded and $1.0 \mathrm{vlpm}$ of fresh smoke to the BBCES aerosol inlet and to a mixing volume with dilution for a collection of other aerosol instruments (Manfred et al., 2018; Adler et al., 2019). The DMA, valves, MFCs, and all other components shown in Fig. 1 were controlled by custom LabVIEW software and synchronized to the timing of the two-position valve shown in Fig. 1c as part of the NOAA shared aerosol inlet.

The inlet apparatus included three separate thermodenuders to enable comparison between different temperatures, but this paper reports data from only one. This denuder consisted of an $80 \mathrm{~cm}$ screen tube $(1.3 \mathrm{~cm}$ i.d.) wrapped in activated charcoal fabric to remove volatilized organic components. The first $40 \mathrm{~cm}$ was heated to $250{ }^{\circ} \mathrm{C}$, and the remaining $40 \mathrm{~cm}$ served as a cool-down region. With a flow rate of $1.0 \mathrm{vlpm}$, the calculated residence time was $3.2 \mathrm{~s}$ and Reynolds number was 114 . The denuders were similar to the design of Huffman et al. (2008), with the major difference that the heated section had charcoal fabric to absorb the volatilized species. The throughput efficiency was found to be less than unity $(86 \pm 4 \%$ for particles between 100 and $300 \mathrm{~nm}$ ) due to thermophoretic wall losses, but the analysis of the aerosol size-independent RI, which is an intrinsic property of the aerosol (Moise et al., 2015), is largely unaffected by these losses. We therefore do not make any corrections to these data.

\subsection{Black carbon and organic aerosol measurements}

Additional instruments sampled from the shared aerosol inlet's mixing volume, shown in Fig. 1c, and those data were used to assess the fraction of black carbon in the total aerosol mass loading of smoke from each fire. A single-particle soot photometer (SP2; Droplet Measurement Technologies, Longmont, CO, USA) measured the concentration of refractory black carbon aerosol, rBC (Schwarz et al., 2006, 2008). The $\mathrm{rBC}$ mass concentration was only retrieved in the mass range corresponding to particles with a volume equivalent diameter of $90-550 \mathrm{~nm}$, assuming a void-free density of $1.8 \mathrm{~g} \mathrm{~cm}^{-3}$. This range typically covers $90 \%$ or more of the accumulation-mode rBC emitted from wildfires. Refractory black carbon has been shown to be experimentally consistent with elemental carbon measured after a thermal denuder within $15 \%$ (Kondo et al., 2011). The uncertainty of the black carbon mass at this concentration is $30 \%$. A compact time-of-flight aerosol mass spectrometer (c-TOF AMS; Aerodyne Research Inc., Billerica, MA, USA) measured organic aerosol (OA) mass (Bahreini et al., 2008, 2009). The uncertainty of the OA mass is typically $\sim 38 \%$ due to standard uncertainties in AMS measurements (Bahreini et al., 2009) but was greater for biomass burning aerosol at the Fire Sciences Laboratory because of additional variability in aerosol volatility due to dilution of the dense smoke. Therefore, we use relative AMS masses in this analysis.

\subsection{BBCES instrument operation at the Fire Sciences Laboratory}

Each measurement day at the Fire Sciences Laboratory included two controlled burns, with 3-4 h of sampling of each burn. The instruments and inlet components were turned on at least $1 \mathrm{~h}$ prior to the first burn. Each sample cycle required 30 min and began with measurements of $\mathrm{CO}_{2}$ and $\mathrm{He}$ to determine the BBCES mirror reflectivity, followed by measurement of the dark noise of the CCD detector with the physical shutter closed. During these BBCES calibrations, the size distribution of the aerosol sample was measured by SMPS. Next, the BBCES and CRDS measured fresh and denuded $\left(250{ }^{\circ} \mathrm{C}\right)$ aerosol with mobility diameters $\left(D_{\mathrm{p}}\right)$ of 150,225 , 300,375 , and $450 \mathrm{~nm}$ for $2 \mathrm{~min}$ each (20 min total). The aerosol mass loading was very high in the burn room (typically $\sim 1 \mathrm{~g} \mathrm{~m}^{-3}$ ) but was reduced by a factor of $\sim 100$ by the DMA and the dilution flows prior to measurement by the BBCES. Therefore the $2 \mathrm{~min}$ averaging time ensured sufficient precision in the spectra and the particle counting, particularly at the larger diameter set points. These DMA diameter set points were chosen to span the observed aerosol size distribution of the smoke. Filtered sample air was measured before and after each set of five measurements. The five mobility diameter measurements allowed RI to be retrieved once every $10 \mathrm{~min}$, alternating between fresh and denuded biomass burning smoke. Between the two daily fires, $\mathrm{NO}_{2}$ 
additions were made to assess the spectrometer stability. The spectrometer wavelength and resolution were calibrated with the output of a $\mathrm{Hg}$ lamp before the first burn, between the first and second burns, and after the second burn.

After the FIREX 2016 study, the BBCES extinction measurements and complex RI retrievals were validated using standard samples of polystyrene latex spheres (PSLs; Nanosphere size standards, Thermo Fisher Scientific Inc., Waltham, MA, USA) and ammonium sulfate (Sigma Aldrich, St. Louis, MO, USA). For these measurements, the aerosols were generated using a custom-built atomizer, and dilution make-up flow was provided by scrubbed and dried air from a compressor. Five or six aerosol sizes were selected, spanning a similar range to those sampled during FIREX. The sampling scheme shown in Fig. 1a and $b$ remained the same, but the shared inlet shown in Fig. 1c was not used. Particle-free air and mirror reflectivity measurements were performed before and after each set of aerosol sizes.

\section{Data analysis}

\subsection{Determination of aerosol optical extinction and mirror reflectivity}

The aerosol optical extinction, $\alpha(\lambda)$, can be determined from the observed change in light intensity in the cavity according to

$\alpha(\lambda)=d_{\mathrm{L}}\left(\frac{1-R(\lambda)}{d}+\alpha_{\text {Rayleigh, }, \mathrm{ZA}}(\lambda)\right)\left(\frac{I_{\mathrm{ZA}}(\lambda)-I(\lambda)}{I(\lambda)}\right)$,

where $\lambda$ is wavelength, $d_{\mathrm{L}}$ is the ratio of the physical cell length to the sample cell length, $R(\lambda)$ is the measured mirror reflectivity, $d$ is the physical cell length, $\alpha_{\text {Rayleigh,ZA }}(\lambda)$ is the Rayleigh scattering of zero air, $I_{\mathrm{ZA}}(\lambda)$ is the reference intensity spectrum, and $I(\lambda)$ is the measured intensity spectrum (Washenfelder et al., 2013). The extinction cross section, $\sigma(\lambda)$, is defined as the optical extinction divided by the total number concentration of aerosol particles, $N$, for the given size distribution:

$\sigma(\lambda)=\frac{\alpha(\lambda)}{N}$.

The most common method for determining $R(\lambda)$ in Eq. (1) is through extinction measurements of two gases with known Rayleigh scattering cross sections, typically $\mathrm{He}$ and $\mathrm{N}_{2}$ or zero air (Washenfelder et al., 2008). Previous BBCES applications in the UV wavelength region often used $\mathrm{He}$ and $\mathrm{N}_{2}$, which have substantially different cross sections (Washenfelder et al., 2013; Flores et al., 2014a; Bluvshtein et al., 2017; Zhao et al., 2017). However, Rayleigh scattering is proportional to $\lambda^{-4}$, and more accurate characterizations of mirror reflectivity at visible wavelengths can be achieved by using a gas with a larger Rayleigh scattering cross section than $\mathrm{N}_{2}$ or $\mathrm{O}_{2}$, particularly when the mirror reflectivity is not very high. We selected $\mathrm{CO}_{2}$ as a stable, inexpensive, nontoxic gas with a large Rayleigh scattering cross section. The Rayleigh scattering cross section of $\mathrm{CO}_{2}$ has been reported (Shardanand and Rao, 1977; Sneep and Ubachs, 2005; He et al., 2018), but it is not as well-known as $\mathrm{N}_{2}$ or $\mathrm{O}_{2}$. We determined it here by introducing mixtures of $\mathrm{CO}_{2}$ in $\mathrm{He}$ to the BBCES instrument, measuring the extinction spectrum for each addition, and deriving the slope of the linear fit of the extinction relative to the $\mathrm{CO}_{2}$ number density.

\subsection{Correction of optical extinction for optical intensity and spectral drift}

Spectral fitting of trace gas absorbers in BBCES extinction spectra often includes a fourth-order polynomial to account for drifts in the cavity, spectrometer, and light source intensity (Platt et al., 2009; Thalman and Volkamer, 2010; Min et al., 2016). While this can be effective for trace gases with highly structured absorbing features measured using mirrors with smoothly varying reflectivity, it is not appropriate for smoothly varying aerosol extinction spectra or for cavity mirrors with reflectivity that varies strongly with wavelength (see Fig. S1). Here, we describe a new method to explicitly account for drifts in the cavity, spectrometer, and light source intensity that affected the calculated $\alpha(\lambda)$ extinction for the visible channel.

We determined that each measured spectrum may be affected by drift in the light source intensity, drift in the spectrometer dark current background counts, and a wavelength shift incurred by the temperature-dependent drifts in the spectrometer optics and that these can each be represented by a scalar parameter. Using a nonlinear LevenbergMarquardt least-squares fitting algorithm, the scalar parameters for these different types of drift were fitted and the drifts removed. The fitting algorithm was tested successfully on spectra of zero air and found to remove nearly all the structure due to intensity and spectrometer drift. This correction was subsequently used on all extinction spectra. Further details for this correction can be found in the Supplement and in Fig. S2.

\subsection{Complex refractive index retrieval}

The aerosol optical extinction derived in Eq. (1) depends on wavelength, aerosol size distribution, and the RI. Measurements of aerosol optical extinction for different size selections can be used to retrieve $n(\lambda)$ and $k(\lambda)$ (Washenfelder et al., 2013; Flores et al., 2014a; He et al., 2018) with assumptions that the aerosol population is internally and externally well-mixed and that the refractive index does not vary systematically with size. For PSL and ammonium sulfate aerosol, this approach was used as described previously (Washenfelder et al., 2013; Flores et al., 2014a). Each $2 \mathrm{~min}$ group of spectra for a single aerosol population was averaged to determine $I(\lambda)$. The aerosol extinction cross section, $\sigma(\lambda)$, 
was then calculated using Eqs. (1) and (2), with values of $I_{\mathrm{ZA}}(\lambda)$ and $R(\lambda)$ linearly interpolated from the nearest measurements. The set of aerosol extinction cross section spectra $\left(\sigma_{\mathrm{D}_{\mathrm{p}}=150 \mathrm{~nm}}(\lambda), \sigma_{\mathrm{D}_{\mathrm{p}}=225 \mathrm{~nm}}(\lambda), \ldots\right)$ and the average aerosol size distribution $N\left(D_{\mathrm{p}}\right)$ for each time interval can then be used to retrieve the complex refractive index, $n(\lambda)+k i(\lambda)$ using a scattering theory.

We use a retrieval algorithm that calculates the expected extinction cross section for a given wavelength, a given RI, and the measured $N\left(D_{\mathrm{p}}\right)$ and compares it to the measured extinction cross section. Since the RI consists of both $n$ and $k$, at least two extinction measurements are required to retrieve these two parameters (Bluvshtein et al., 2012). We use five diameter set points to increase the accuracy of the retrieval. A least-squares minimization fit is used to identify the $n$ and $k$ values that minimize $\chi^{2}$ for each wavelength:

$\chi^{2}(\lambda)=$

$$
\sum_{D_{\mathrm{p}}}^{N=5}\left(\frac{\sigma_{\text {calculated }}\left(n, k, \lambda, D_{\mathrm{p}}\right)-\sigma_{\text {measured }}\left(\lambda, D_{\mathrm{p}}\right)}{\sigma_{\text {measured }}\left(\lambda, D_{\mathrm{p}}\right)}\right)^{2},
$$

where $\sigma$ represents the extinction cross section from Eq. (2).

Previous work has assumed spherical aerosol populations that are well-represented by Mie theory and have easily measured size distributions (Washenfelder et al., 2013; Flores et al., 2014a; He et al., 2018). The biomass burning aerosol produced from some of the fires at the Fire Sciences Laboratory was fractal and strongly absorbing. This required two improvements to the retrieval algorithms, described further below: (1) the incorporation of two methods for size distribution measurements (the OPC and the SMPS) to better characterize $N\left(D_{\mathrm{p}}\right)$ and (2) the incorporation of two scattering theories, Mie and Rayleigh-Debye-Gans (RDG), to represent both spherical and fractal aerosol.

\subsubsection{Treatment of the aerosol size distribution}

The DMA transmits ionized particles of a specified mobilityto-charge ratio, resulting in a small number of doubly and triply charged particles that appear as particles with mobility diameters approximately 2 and 3 times greater than expected. The relative contribution of the singly, doubly, and triply charged particles to the total size distribution depends on the ambient aerosol size distribution as well as the ratio of sheath flow to aerosol flow in the DMA. To determine the aerosol size distribution, we iteratively adjusted an assumed input size distribution transmitted through the DMA transfer function until the theoretical particle concentration produced by the inversion matched that measured by the CPC (Twomey, 1975; Markowski, 1987). Once the input size distribution was determined, the DMA transfer function was used to estimate the size distribution of the aerosol exiting the DMA as the voltage was changed to select different peak diameters.

For spherical, non-absorbing particles, such as ammonium sulfate aerosol, we expect the SMPS scans and inversions to yield accurate size distributions, as the contribution of multiply charged particles is straightforward to calculate for spherical particles with well-known mobility diameters. If the aerosol is significantly non-spherical, such as fractal BC expected from some biomass burning smoke, then the transmission through the DMA is affected by the aerodynamic resistance of the sheath flow (Adler et al., 2019), the contribution of multiply charged particles is difficult to ascertain, and the resulting size-selected aerosol may not match the actual particle size. We therefore do not attempt any correction to the SMPS scans for BC aerosol; the inverted size distributions represent electrical mobility diameter rather than geometric diameter.

An alternate aerosol sizing instrument is the OPC, which sizes particles by measuring the light scattered into a wideangle lens or mirror mounted perpendicularly to the direction of laser propagation. The integrated side-scattering intensity increases monotonically with particle size for non-absorbing particles. However, a theoretical correction must be made for slightly or highly absorbing particles. By calculating the scattered light expected as a function of angle, using either Mie or RDG theory (see Sect. 3.3.2), one can integrate over the solid angle of the LAS measurement optics to get a corrected LAS size distribution. We discuss this correction further in Sect. 4.6.

Theoretical particle losses between the DMA and the BBCES instrument were calculated (von der Weiden et al., 2009) as a function of particle diameter and were accounted for in the size distribution calculations. These losses were generally small, with fewer than $1 \%$ loss in the relevant particle diameter range of $100-800 \mathrm{~nm}$ for this analysis.

\subsubsection{Mie theory and Rayleigh-Debye-Gans theory}

Two theories are used in this paper to characterize the optical properties of the measured aerosol. Mie theory is a solution to Maxwell's equations that describes the interaction of light with homogeneous, spherical particles when the diameter of the sphere is similar to the wavelength of light (Bohren and Huffman, 1983). It is a truncated infinite series representing the electromagnetic field scattered from spheres. For the representation used in this work, the theory is valid when the dimensionless size parameter $(x=\pi d / \lambda)$ is approximately 1 . We adapted the Fortran code presented in Bohren and Huffman (1983) for use in Igor Pro (Igor Pro; WaveMetrics, Inc., Lake Oswego, OR, USA). The code calculates light scattering and absorption for homogeneous spheres or homogeneous spheres with a concentric coating.

Rayleigh-Debye-Gans theory has often been applied to calculate the interaction of light with fractal aggregates from biomass burning (Sorensen, 2001). Spherical approximations and Mie theory are poor representations of these particles, and more detailed models such as the discrete dipole approximation are very computationally expensive. RDG theory divides a particle into small-volume elements, which are 
each treated as independent Rayleigh scatterers. Fractal aggregates can be represented by the relatively simple parameterization

$N=k_{0}\left(\frac{R_{\mathrm{g}}}{a}\right)^{D_{\mathrm{f}}}$,

where $N$ is the number of monomer spherules per aggregate, $k_{0}$ is the fractal prefactor, $R_{\mathrm{g}}$ is the radius of gyration, $a$ is the monomer radius, and $D_{\mathrm{f}}$ is the fractal dimension (Sorensen, 2001; Smith and Grainger, 2014). The theory is valid when the relative refractive index and the dimensionless size parameter of the monomer can be described as $|n-1|<1$ and $x \leq 0.3$ (Farias et al., 1996). Code to calculate the expected extinction cross section as a function of the input parameters was written in Igor Pro, following Sorensen (2001).

\subsection{Precision and accuracy of measured aerosol extinction and retrieved RI}

The accuracy of the measured aerosol extinction, $\lambda$, was determined by propagating the known uncertainties of the measurement. The precision in the $I(\lambda)$ spectrum is shot noise limited at the CCD. Figure S1b demonstrates that error from this photon counting is negligible compared to the other uncertainties. The majority of the error is attributed to uncertainty in the Rayleigh scattering cross sections of zero air $( \pm 2 \%)$ and $\mathrm{CO}_{2}( \pm 2 \%)$ as well as uncertainty in the measured temperature $( \pm 0.5 \%)$ and pressure $( \pm 0.5 \%)$ and flow rates $( \pm 0.3 \%)$ (Washenfelder et al., 2013). Summed in quadrature, the total calculated uncertainty in $\alpha(\lambda)$ is approximately $\pm 3 \%$, with some wavelength dependence. The uncertainty in the extinction cross section, $\sigma(\lambda)$ as shown in Eq. (2), is derived from summing in quadrature the error in $\alpha(\lambda)$ and the error in $N$. The error in the particle counting, $N$, by the CPC is due to the uncertainty in the flow rate and the variability in the number of particles entering the CPC. The last factor is highest for the largest diameter set points due to the low number of particles, and thus the uncertainty in $N$ typically lay between \pm 5 and $\pm 10 \%$ and was highest at the largest aerosol diameter set points. The standard deviations for all measurements are indicated in the figures by shaded error bars. The derived lower detection limit as a function of wavelength is shown in Fig. S1b and spans $1 \times 10^{-8}$ $7 \times 10^{-8} \mathrm{~cm}^{-1}$. Extinction values measured during FIREX 2016 were generally greater than $1 \times 10^{-7} \mathrm{~cm}^{-1}$ and therefore within the measurable range of the BBCES.

To ascertain the uncertainty in the retrieved RI, we retrieve values three times: once for the best estimate of $\sigma(\lambda)$, and once for the upper and lower bounds of $\sigma(\lambda)$. This is likely a conservative estimate of the total uncertainty and is shown as shaded error bars in the figures. The RI was retrieved with a resolution of 0.01 in both $n$ and $k$, so if the upper or lower bound of the retrieved RI was within 0.01 of the best estimate, those error bars appear to be zero. In that case, the error should be interpreted as being no more than 0.01 .

\section{Results and discussion}

We present the results of measurements taken during and after the FIREX 2016 deployment. First, the measurement of the $\mathrm{CO}_{2}$ Rayleigh scattering cross section between 360 and $720 \mathrm{~nm}$ is presented, along with the measurement of daily additions of known concentrations of $\mathrm{NO}_{2}$ throughout the duration of the Fire Sciences Laboratory experiments, to ascertain the long-term stability and accuracy of the BBCES extinction cross section measurements. Next, we present retrievals of the RI of known laboratory standards - PSL and ammonium sulfate - across a wider wavelength range than has previously been measured. We use these measurements to assess the reliability of the two size distribution methods. We examine measurements of two contrasting fires from the Fire Sciences Laboratory, one dominated by spherical $\mathrm{BrC}$ particles and the other by fractal $\mathrm{BC}$ particles, and demonstrate that the first can be reasonably characterized using Mie theory, while the second cannot and requires Rayleigh-Debye-Gans theory. These two fires are the same as presented in Manfred et al. (2018), and we follow that work in denoting the two fires Fire A and Fire B, respectively. Finally, RIs were retrieved for 13 fires assuming Mie theory, and the quality of the fits is related to the black carbon content of the smoke, demonstrating that smoke with higher BC generally cannot be fit well with Mie theory.

\section{1 $\mathrm{CO}_{2}$ Rayleigh scattering cross section}

Figure 2 shows the measured $\mathrm{CO}_{2}$ Rayleigh scattering extinction spectra, determined from six fractional concentrations of $\mathrm{CO}_{2}$ in He that evenly span $0-1$. The mirror reflectivity, $R(\lambda)$, was determined here using pure $\mathrm{He}$ and zero air standards. The $\mathrm{CO}_{2}$ extinction spectrum, $\alpha(\lambda)$, at each concentration was determined using Eq. (1), with He replacing zero air as the reference gas. Spectral peaks attributed to absorption by $\mathrm{O}_{2}$ near $688 \mathrm{~nm}$ (Greenblatt et al., 1990) and the $\mathrm{O}_{4}$ oxygen dimer near 477,577 , and $630 \mathrm{~nm}$ (Hermans, 2011) were fitted and removed prior to further analysis. At each wavelength, the measured extinction (units of $\mathrm{cm}^{-1}$ ) was plotted against the number density of $\mathrm{CO}_{2}$ (units of $\mathrm{cm}^{-3}$ ), and the slope of the linear fit is the Rayleigh scattering cross section (units of $\mathrm{cm}^{2}$ ).

The $\mathrm{CO}_{2}$ Rayleigh scattering cross section determined for the two BBCES channels and CRDS channel agree well, as shown in Fig. 2. A power law fit to the BBCES data from $360-720 \mathrm{~nm}$ is parameterized as $\sigma_{\text {Rayleigh, } \mathrm{CO} 2}=$ $1.43 \times 10^{-15} \times \lambda^{-4.036}$. Three literature values for the $\mathrm{CO}_{2}$ Rayleigh scattering cross section are also plotted in Fig. 2. These were experimentally determined using a scattering chamber (Shardanand and Rao, 1977), CRDS (Sneep and Ubachs, 2005), and BBCES (He et al., 2018). Our power law fit is consistent with all prior measurements within $10 \%$ at all wavelengths and is within $5 \%$ of the two more recent studies at lower wavelengths where the Rayleigh scattering 


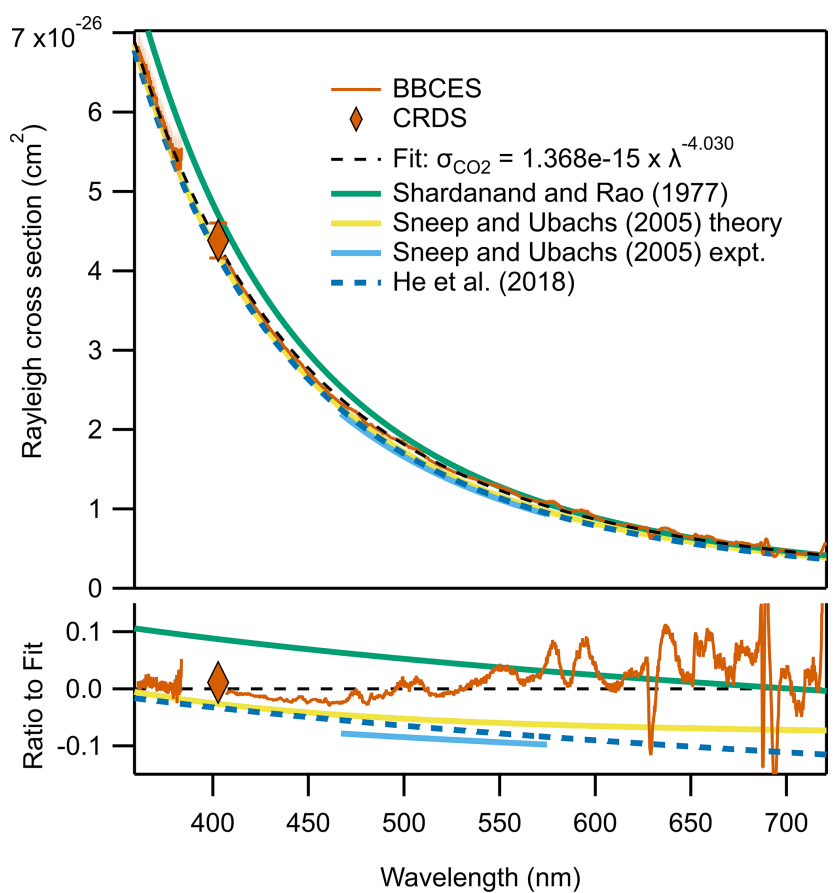

Figure 2. The measured Rayleigh scattering cross section of $\mathrm{CO}_{2}$. The red solid line and filled diamond show the measurement by BBCES and CRDS, respectively, with the black dashed line showing the power law fit to the measured data. Several other literature parameterizations are shown as solid colored lines and discussed further in the text. The ratio of each trace relative to the power law fit derived here is shown at the bottom, and all are within $10 \%$ of the fit derived here. The small peaks and valleys observed in the experimental fit are due to imperfect subtraction of peaks from $\mathrm{O}_{2}$ and the $\mathrm{O}_{4}$ oxygen dimer.

is greater. We use the power law parameterization of $\mathrm{CO}_{2}$ Rayleigh scattering cross section for the retrievals described below.

\subsection{Standard additions of $\mathrm{NO}_{2}$}

To assess the long-term stability of the instrument, we introduced concentrations of $\mathrm{NO}_{2}$ during each of the 16 measurement days at the Fire Sciences Laboratory, using the flow system shown in Fig. 1b. Each set of additions included four $\mathrm{NO}_{2}$ concentrations from 0 to 72 ppbv. Measured $\mathrm{NO}_{2}$ number densities were retrieved by fitting the $\mathrm{NO}_{2}$ absorption cross section (Vandaele et al., 1998) to the extinction, $\alpha(\lambda)$, with shift and stretch of the literature spectrum to account for discrepancies in the BBCES wavelength calibration (Min et al., 2016). A small amount of HONO was observed in the UV channel, but it has distinct spectral peaks and did not interfere with the $\mathrm{NO}_{2}$ fits. The measured $\mathrm{NO}_{2}$ concentrations are compared to the nominal concentrations determined by the flow rates and shown in Fig. S3. The $r^{2}$ values are greater than 0.99 and the slopes vary from $0.8-1$, with a slight downward drift in both parameters over time. This could be due to conversion of $\mathrm{NO}_{2}$, as the BBCES is designed to minimize particle losses, not $\mathrm{NO}_{2}$ conversion on surfaces. It is also possible that the $\mathrm{NO}_{2}$ calibration tank concentration changes over time, as the output of these tanks is known to deviate significantly from the manufacturer's specified concentration (Chilton et al., 2005). The two fires examined in this paper - Fires A and B - occurred on 31 October and 1 November 2016, and Fig. S3 shows agreement of $\pm 7 \%$ with the nominal $\mathrm{NO}_{2}$ concentration on those $2 \mathrm{~d}$.

\subsection{Refractive index retrieval for PSL}

We atomized five aqueous solutions of monodisperse PSL with diameters from 150 to $400 \mathrm{~nm}$ and passed the resulting aerosol flow through a DMA to remove any clumped particles or small spheres of surfactant (Miles et al., 2010; Thalman and Volkamer, 2010). The size-selected aerosol was monitored by a UHSAS OPC and found to be consistent within uncertainty with the manufacturer-specified mode diameter and Gaussian distribution. SMPS-derived size distributions of PSL were not measured, due to their narrow diameter distribution. The intensity spectra and size distributions were averaged for approximately $90 \mathrm{~s}$ at each diameter set point, and extinction cross sections were derived using Eqs. (1) and (2), as described in Sect. 4.1 and 4.2. To minimize errors due to changes in the light source and optical stability, we measured the mirror reflectivity before and after each PSL diameter set point, in addition to using the fitting algorithm described in Sects. 3.2 and $\mathrm{S} 1$.

The resulting extinction cross sections for the five PSL diameters are shown in Fig. 3a. Calculated extinction cross sections from the measured OPC size distribution and the RI reported by Nikolov and Ivanov (2000) are also shown, and these agree with our measured extinction cross sections within the instrument uncertainty. The largest error bars appear in the $D_{p}=400 \mathrm{~nm}$ extinction cross section. It was difficult to produce PSL solutions with sufficiently high concentrations at the larger diameters, and the extinction cross section, which is the total extinction divided by the total particle counts, is therefore highly sensitive to the accuracy of the particle counting. To reduce error in the RI retrieval, we exclude the $400 \mathrm{~nm}$ spectrum from the RI retrieval.

The retrieved RI is shown in Fig. $3 b$. We find that $n$ varies from 1.65 to 1.57 between 360 and $700 \mathrm{~nm}$, while $k=0$ throughout, as expected for purely scattering particles. We empirically fit $n$ to a third-order polynomial function of wavelength as $n=2.30-0.0035 \times \lambda+\left(6.05 \times 10^{-6}\right) \times$ $\lambda^{2}-\left(3.62 \times 10^{-6}\right) \times \lambda^{3}$ across the measured spectral range. Nikolov and Ivanov (2000) measured the RI of PSL spheres using a direct scattering photodetector and found a gradual decrease from $1.62+0.00 i$ to $1.59+0.00 i$ over the wavelength region 450 to $700 \mathrm{~nm}$, as shown in Fig. 3b. Several other recent experimental studies (Garvey and Pinnick, 1983; Abo Riziq et al., 2007; Dinar et al., 2008; Washenfelder et al., 

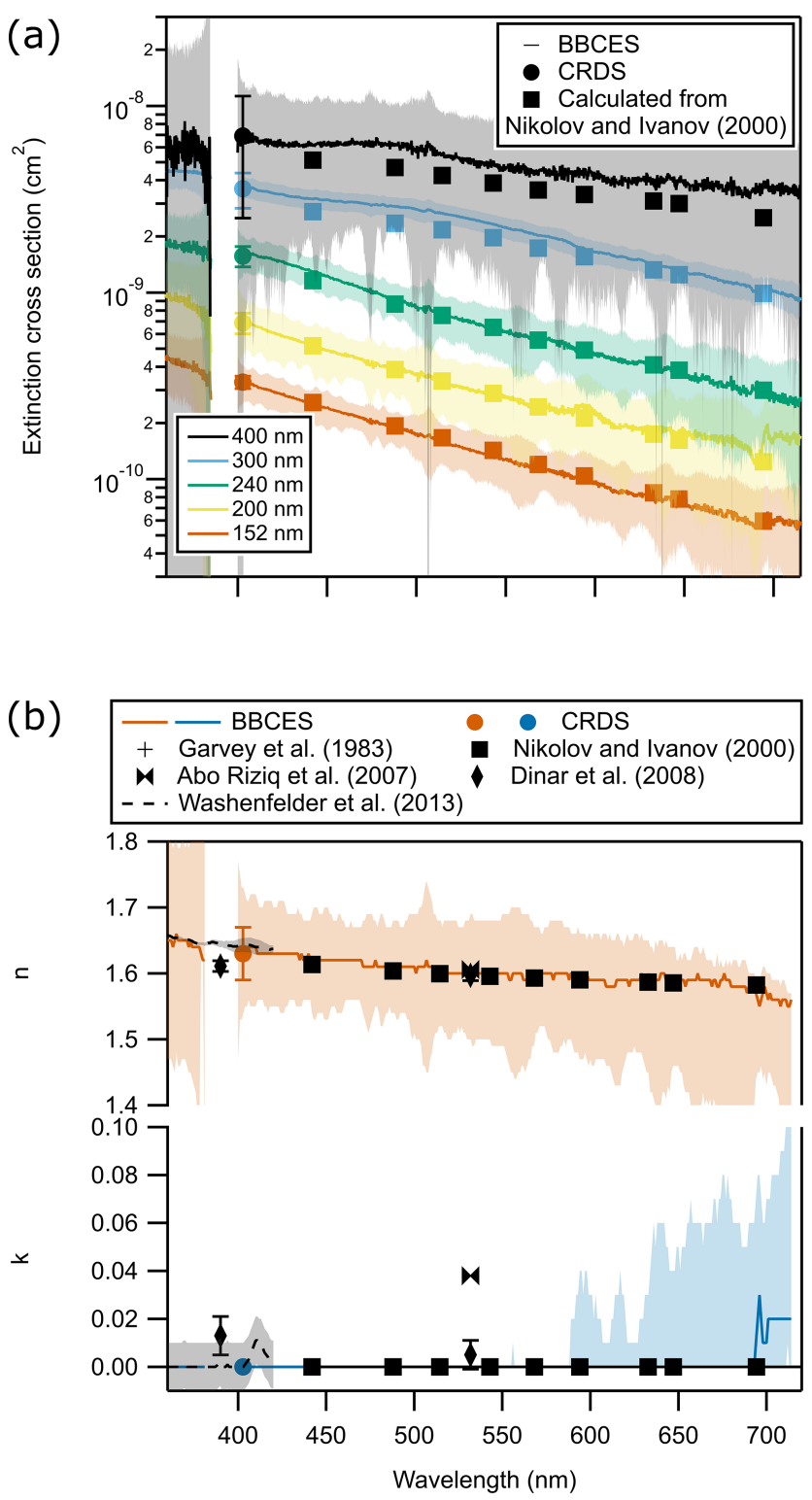

Figure 3. (a) Measured extinction cross sections for five diameters of PSLs are shown as solid lines, with $2 \sigma$ error bars designated by shaded regions. The theoretical extinction cross section calculated from the RI of Nikolov and Ivanov (2000) and the measured aerosol size distribution is shown as filled squares for each diameter set point. (b) The retrieved RI of PSL spheres derived from the measurement in (a) and the size distribution measured by the OPC. The RI is retrieved to the nearest 0.01 , and the absence of a visible upper or lower error bar implies that the calculated error is less than 0.01 . The RIs retrieved by Nikolov and Ivanov (2000) are shown as black squares. The error increases at longer wavelengths due to increased uncertainty in the $\mathrm{CO}_{2}$ Rayleigh scattering spectrum.

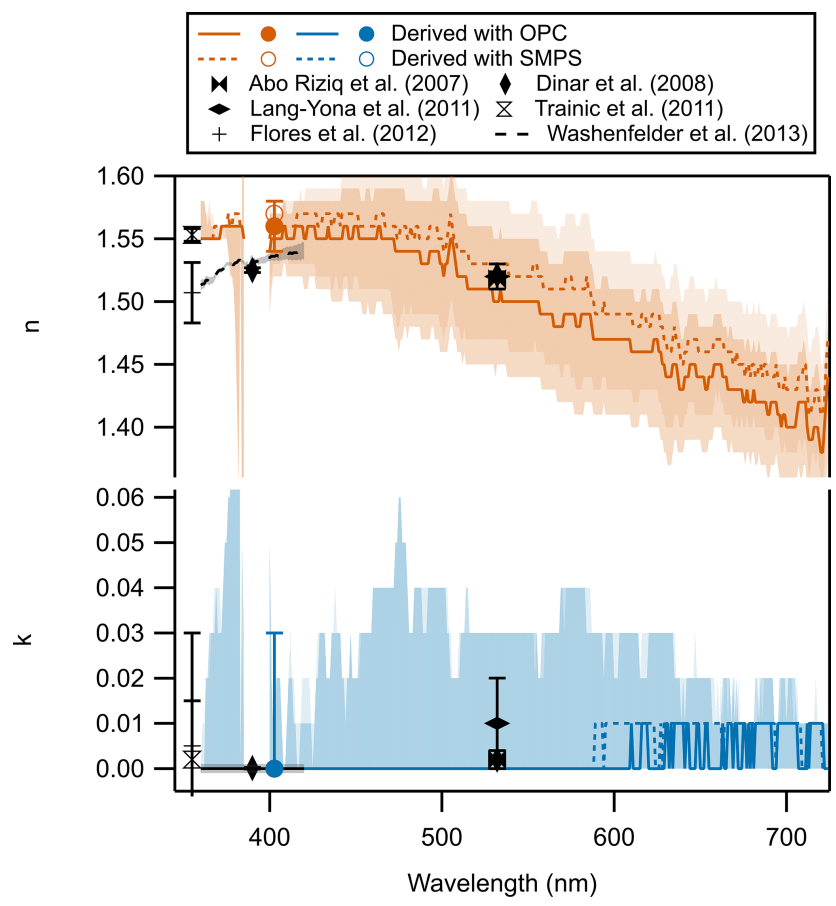

Figure 4. The RI retrieved for dry ammonium sulfate aerosol, using two particle size distribution methods: an OPC (LAS 3340) and a DMA operating in SMPS mode. Both retrievals agree well with literature values for ammonium sulfate between 350 and $550 \mathrm{~nm}$. As in Fig. 3, the RI is retrieved to the nearest 0.01 , and an absence of a visible error bar implies that the calculated error is smaller than 0.01 .

2013) at 390 and $532 \mathrm{~nm}$ are also shown and agree well with our results.

\subsection{Refractive index retrieval for ammonium sulfate}

Figure 4 shows the retrieved RI for ammonium sulfate aerosol, using the two different size distribution methods. Ammonium sulfate particles were atomized from a $6.0 \mathrm{~g} \mathrm{~L}^{-1}$ aqueous solution of ammonium sulfate in distilled water and then dried to less than $5 \% \mathrm{RH}$ to minimize the water content. Extinction cross sections were determined at diameter set points from $150-450$ in $75 \mathrm{~nm}$ increments. The aerosol size distribution was measured continuously after the DMA by a UHSAS OPC, which was independently calibrated for ammonium sulfate particles prior to the experiment (Kupc et al., 2018). Additionally, SMPS scans were taken before and after each set of aerosol diameter set points, and an inversion algorithm was used to derive the full size distribution of the atomized aerosol entering the DMA. Spurious peaks in the size distribution at diameters greater than $750 \mathrm{~nm}$ were removed. Section S2 describes this correction further. The DMA transfer function was then used to determine the aerosol size distribution at each diameter set point. 
The RI values in Fig. 4 range from $1.55+0.00 i$ at $360 \mathrm{~nm}$ to $1.40+0.01 i$ at $720 \mathrm{~nm}$, though the error bars for the imaginary component span $0 i$ and thus cannot be distinguished from a non-absorbing aerosol. The results from the two size distribution methods agree well, indicating that the SMPS size distribution is an accurate assessment of the aerosol population. We empirically fit the $n$ derived by OPC as a third-order polynomial function of wavelength as $n=0.69+$ $0.0052 \times \lambda-\left(9.85 \times 10^{-6}\right) \times \lambda^{2}+\left(5.51 \times 10^{-6}\right) \times \lambda^{3}$ across the entire spectral range. Recent literature values measured by CRDS at 355, 390, 405, and $532 \mathrm{~nm}$ are shown and summarized in Washenfelder et al. (2013). Few measurements of ammonium sulfate RI have been reported at wavelengths greater than $532 \mathrm{~nm}$. The calculated uncertainty is higher at longer wavelengths due to increased uncertainty in the Rayleigh scattering at those wavelengths.

\subsection{Refractive index retrieval for aerosol dominated by brown carbon (Fire A)}

Fire A (no. 086) was a lodgepole pine (Pinus contorta) fire, with a mixture of small logs, litter duff, and canopy branches with low moisture content, intended to be representative of wildfire fuel composition. The smoke was dominated by $\mathrm{BrC}$ with a small contribution from fractal soot-like particles, as shown by the large decrease in number and mode volume when the aerosol was thermodenuded (Manfred et al., 2018). This implies that the majority of the particles consisted of volatile organic matter that was efficiently vaporized in the thermodenuder. We assume that the volatile organic matter has spherical or near-spherical morphology that can be represented using Mie theory.

The retrieved RI values for undenuded aerosol measured $1 \mathrm{~h}$ after fire ignition are shown in Fig. 5a for one $10 \mathrm{~min}$ measurement cycle. Both SMPS and OPC size distributions were available for this set of extinction cross sections, and two diameters are displayed in Fig. 5b. However, there are some differences between the two size distribution measurements. First, as in the ammonium sulfate retrieval in Sect. 4.4, the SMPS inverted full size distribution has some spurious values at diameters above $550 \mathrm{~nm}$ which are not observed in the OPC and which skew the size distributions to higher diameters. Therefore, we again apply an upper diameter threshold, above which the SMPS size distributions are set to zero. Second, the OPC size distribution for every diameter set point shows a small peak near $100 \mathrm{~nm}$. That these small particles passed through the DMA at larger diameter set points suggests that they are small fractal particles, which were selected by the DMA due to their relatively large aerodynamic diameter. Scanning electron microscopy images from the denuded channel for this fire confirm the presence of small fractal particles (Manfred et al., 2018). These particles are quite small and therefore do not contribute much to the total aerosol extinction, but for the larger diameter set points they comprise a significant percentage of the total number of particles. There-
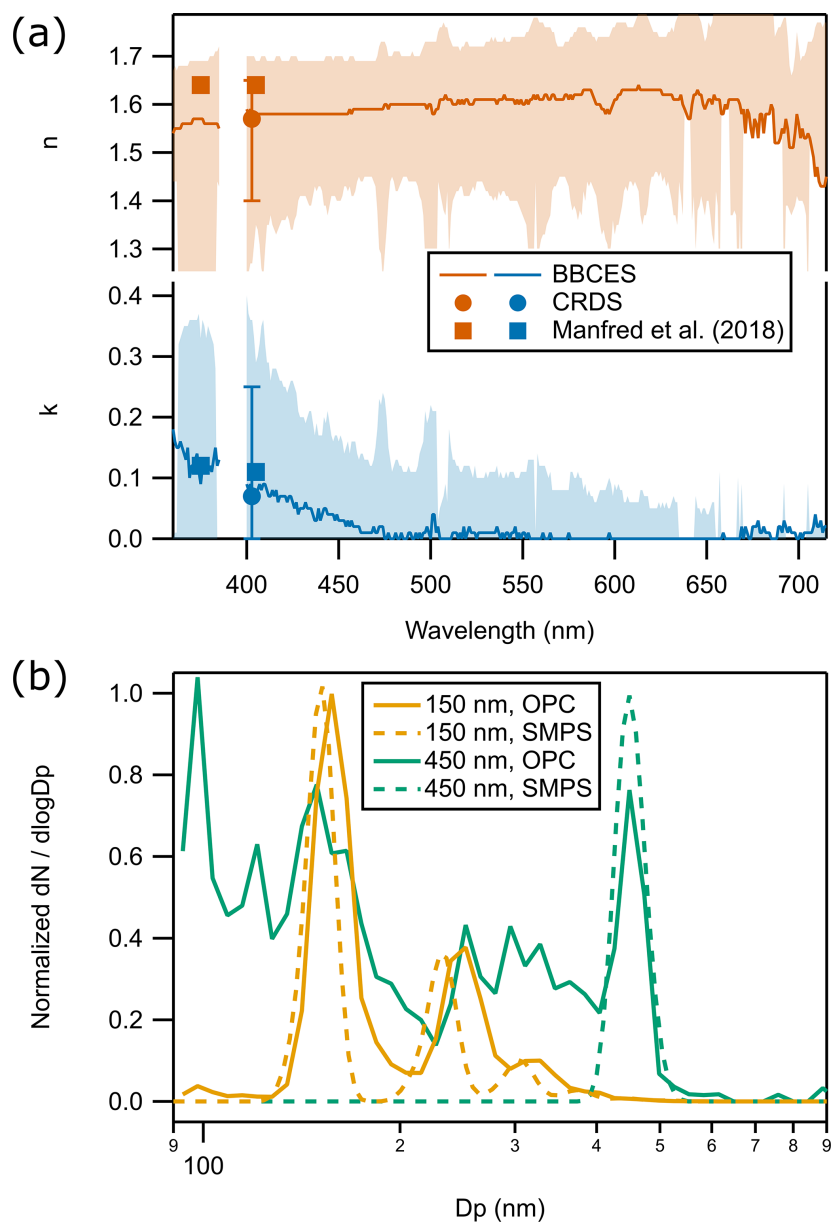

Figure 5. (a) Retrieved RI of undenuded smoke during Fire A, a primarily brown carbon fire. The BBCES and CRDS retrievals are shown as solid lines and circular markers and are calculated to the nearest 0.01 . The squares indicate the assumed RI in Manfred et al. (2018) for this fire. The increase in $k$ with decreasing wavelength is characteristic of brown carbon aerosol. (b) The normalized size distribution of the aerosol from the OPC and the SMPS for two size set points: 150 and $450 \mathrm{~nm}$. The $150 \mathrm{~nm}$ OPC measurement has a small peak near $100 \mathrm{~nm}$ but otherwise shows reasonable agreement with the SMPS, while the $450 \mathrm{~nm}$ set point OPC distribution shows that a significant fraction of the aerosol is smaller than $450 \mathrm{~nm}$, which is not reflected in the SMPS estimate. The other size set points lie in between these two extremes.

fore, we must explicitly include these small particles as part of the size distribution.

Finally, it can be seen in Fig. 5b that the main mode diameter for each set point is approximately $5 \%$ higher in the OPC than the intended set point, as indicated by the mode diameter in the SMPS. The LAS OPC is calibrated for ammonium sulfate particles, assuming an RI of $1.52+0.00 i$. If these brown carbon particles scatter light more effectively than ammonium sulfate particles, then the OPC will interpret this increased light scattering as a larger particle. This also holds true for the small $\sim 100 \mathrm{~nm}$ peaks, which likely 
consist of BC particles with an RI very different from that of ammonium sulfate. Therefore, the sizing of these particles by the OPC may be somewhat incorrect.

Despite these caveats, we use the LAS size distribution without further modification for the RI retrieval in Fig. 5a. We find that the real component of the retrieved RI varies from 1.55 to 1.60 , while the imaginary component steadily increases from $\sim 0 i$ to $0.25 i$ as the wavelength decreases from $550-360 \mathrm{~nm}$. This is highly characteristic of $\mathrm{BrC}$ aerosol and consistent with previous estimates of the complex refractive index of fresh biomass burning aerosol summarized in Bluvshtein et al. (2017). Furthermore, these observations differ significantly from the measured RI of $\sim 1.8+0.01 i$ for spherical BC described as tar balls by Chakrabarty et al. (2010), indicating that the aerosol population measured here does not have a significant contribution from tar balls. At the OPC laser wavelength of $663 \mathrm{~nm}$, the retrieved RI is $(1.61 \pm 0.14)+(0.00 \pm 0.06) i$. Particles with this RI will scatter light slightly more efficiently than ammonium sulfate particles, and therefore the LAS will attribute this scattered light to a slightly larger particle. Therefore, this result is consistent with our finding that the LAS mode diameters are slightly higher than the diameter set point. However, we do not attempt to correct the LAS diameters further, as that analysis is complicated by the small number of fractal particles also observed. Manfred et al. (2018) assumed a typical RI for brown carbon (Dinar et al., 2008), shown as filled squares at 375 and $405 \mathrm{~nm}$, to model the measured phase function from this fire, with good results. We find good agreement with those assumed RIs within instrumental uncertainty.

\subsection{Refractive index retrieval for aerosol dominated by black carbon (Fire B)}

Fire B (no. 085) was a sage (Artemisia) fire that produced smoke with a high $\mathrm{BC}$ content, as evidenced by the minimal change in particle counts and volume between the fresh and thermodenuded smoke (Manfred et al., 2018). Furthermore, Manfred et al. (2018) demonstrated that the measured phase function for this aerosol population could not be accurately fit assuming Mie theory and a typical BrC RI. Instead, they used Rayleigh-Debye-Gans theory, along with two different parameterizations of the fractal particles, to fit the measurement. As described in Sect. 3.3.2, RDG theory treats fractal particles as an aggregate of many smaller monomers, and the input parameters describe the number of monomers, their configuration in the aggregate, and the extinction properties of each monomer.

Unfortunately, neither size distribution method used here can accurately constrain these parameters well. The SMPS size distributions are inaccurate because fractal particles have mobility diameters that differ significantly from their geometric diameters. The OPC size distributions yield more useful information because they measure scattered light within a certain solid angle range, which is later attributed to a certain particle diameter. Only purely scattering and very slightly absorbing particles display monotonically increasing scattering as a function of increasing particle diameter. Highly or moderately absorbing particles tend to side-scatter significantly less than scattering particles to the angles the LAS is most sensitive to, and the scattering often non-monotonically increases as particle size increases (Szymanski et al., 2009). Therefore, a large diameter range of absorbing particles has similar scattering properties and cannot be distinguished, as illustrated in Fig. S5. However, we can make an adjustment to the measured OPC size distributions. As described in Sect. 3.3.2, we use RDG theory to predict the side scatter into the OPC collection optics for particles as a function of the number of monomers, $N_{\mathrm{p}}$, while holding the other parameters in Eq. (4) constant. This allows us to treat the nominal OPC size distribution as a distribution of monomers in the fractal particle. We can then use the same RDG parameters to estimate the extinction cross section and compare it to the measured spectra. Because the RI retrieval is so sensitive to an accurate representation of the particle size, we do not attempt to fit any of the RDG parameters. Instead, we show the expected cross sections for two plausible RDG parameterizations of BC particles.

Figure 6 shows the measured extinction cross sections for the five diameter set points. These spectra were taken $1 \mathrm{~h}$ after the fire was ignited and represent the aerosol that passed through the thermodenuder. Therefore, the majority of organic coatings that might complicate the analysis are removed prior to measurement. Following Manfred et al. (2018), we use two parameterizations. Both assume an $\mathrm{RI}$ for $\mathrm{BC}$ of $1.95+0.8 i$ (Bond and Bergstrom, 2006) and an individual monomer diameter of $50 \mathrm{~nm}$. The first is meant to represent fractal particles from fossil fuel combustion. It assumes a prefactor of 1.2 and a fractal dimension of 1.75 (Sorensen, 2001). The second represents sage biomass burning and consists of a prefactor of 2.56 and a fractal dimension of 1.79 (Chakrabarty et al., 2006). The two parameterizations are shown in Fig. 6a and b. The fossil fuel parameterization yields the closer approximation of the measured data, but the measurement lies in between the two parameterizations. This is consistent with the results of Manfred et al. (2018), in which the measured phase function for thermodenuded smoke from Fire B lay in between the two parameterizations.

\subsection{Summary of refractive index retrievals for $\mathbf{1 3}$ fires during FIREX}

We place the Fire A and B retrievals in the context of the other FIREX measurements by analyzing the quality of the RI retrieval method assuming Mie theory and relating these values to the fraction of aerosol that is black carbon. The $\mathrm{BC} /(\mathrm{BC}+\mathrm{OA})$ fraction was calculated relative to the largest $\mathrm{BC}$ fraction for 13 fires for which the data were avail- 

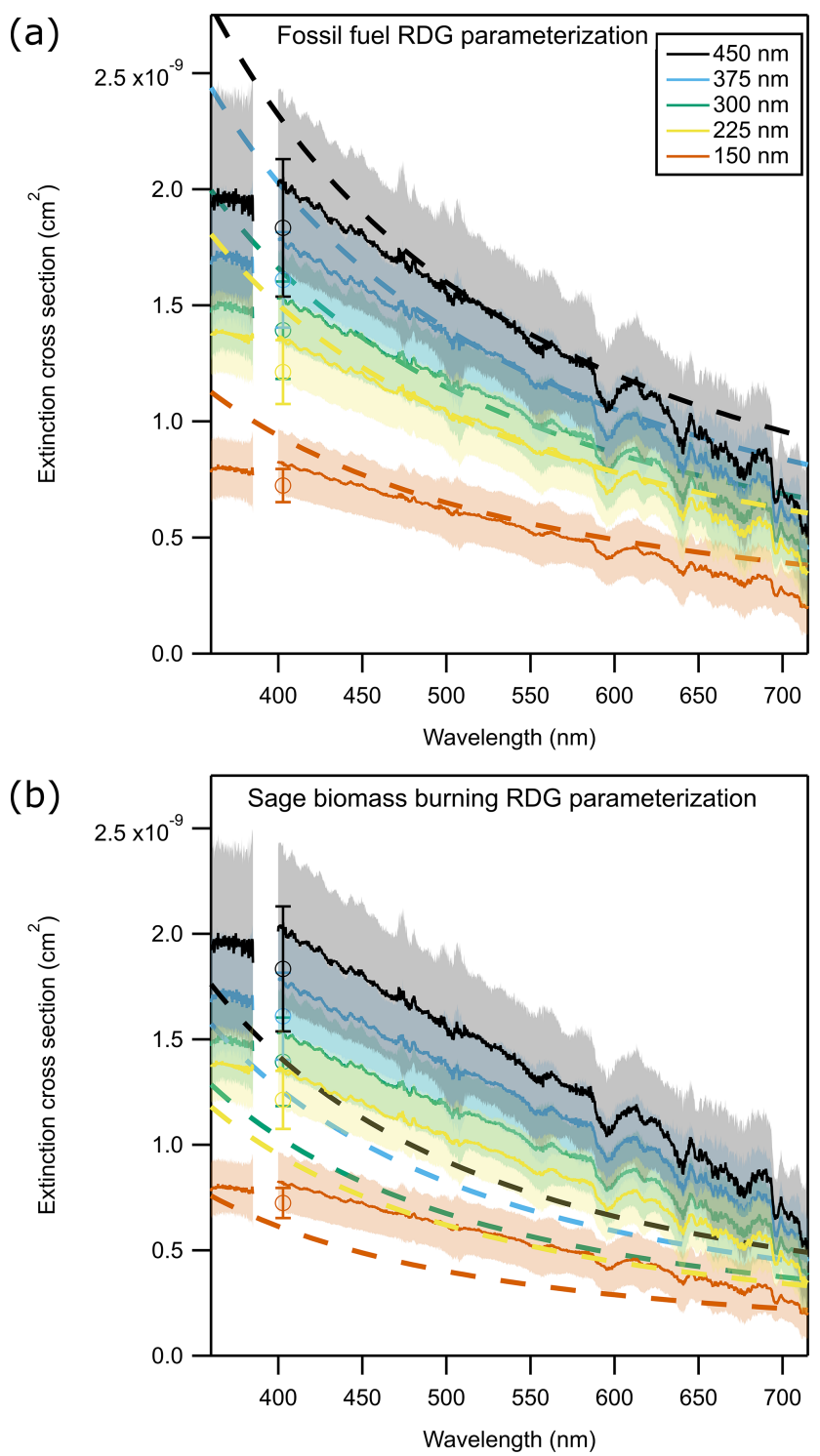

Figure 6. Measured extinction cross section of thermodenuded black carbon dominated aerosol in Fire B are shown as the thin solid lines. Calculated extinction cross section for different RDG parameters (Eq. 4) are shown in each panel. (a) Fossil fuel RDG parameters from Sorensen (2001). (b) Biomass burning RDG parameters for sage from Chakrabarty et al. (2006). The measurement lies between these two parameterizations, thereby constraining the RDG prefactor and fractal dimension, but is closer to the fossil fuel parameterization.

able from the average SP2 black carbon mass and the relative AMS organic aerosol mass, and the error bars were derived from propagating the two instrument uncertainties. Only aerosol that bypassed the thermodenuder was used in this analysis, in order to quantify fresh non-denuded smoke. We elected to evaluate the RI retrieval as a function of the $\mathrm{BC} /(\mathrm{BC}+\mathrm{OA})$ ratio instead of the mass combustion efficiency, as $\mathrm{BC} /(\mathrm{BC}+\mathrm{OA})$ has been shown to more strongly

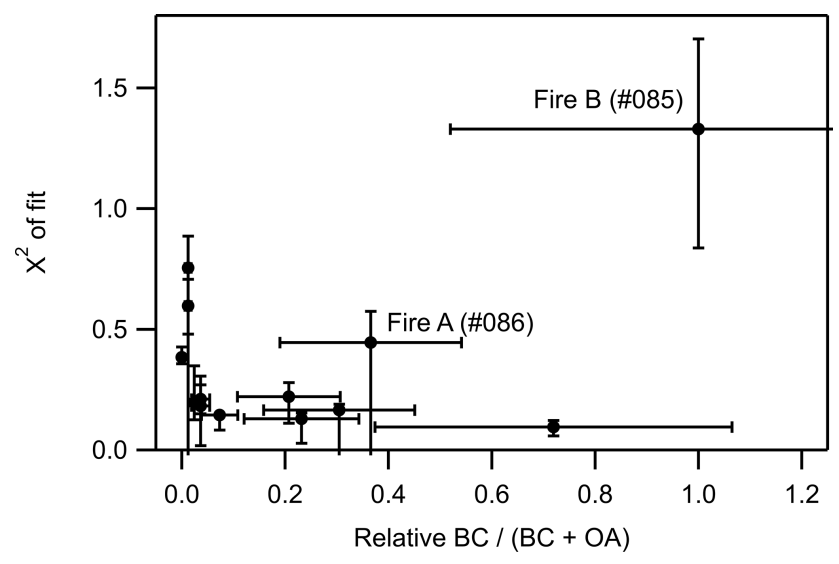

Figure 7. An analysis of 13 fires at the Fire Sciences Laboratory, including the two presented in detail in this paper. Each fire was analyzed identically in this figure. For each fire, the $\chi^{2}$ of the retrieval fit at $\lambda=475 \mathrm{~nm}$ assuming Mie theory is plotted against the relative fraction of total aerosol that is BC. There is a correlation between the $\mathrm{BC}$ fraction and the quality of the fit assuming Mie theory. Fire $\mathrm{B}$ has a far higher fraction of $\mathrm{BC}$ than the other fires and is fit very poorly assuming Mie theory, while Fire A is fit more accurately by Mie theory. The majority of fires have a smaller BC contribution than either Fire A or B and are generally fit reasonably well assuming Mie theory. Note that we have plotted relative BC fraction rather than absolute fraction. Significant uncertainties in the AMS data make the absolute fraction difficult to accurately assess, as described in Sect. 2.6, but the relative fraction is still robust. Therefore, Fire $\mathrm{B}$, which had the highest $\mathrm{BC}$ fraction, is defined here as 1 , and the $\mathrm{BC}$ fractions for the other fires are scaled relative to Fire $\mathrm{B}$.

correlate with single scattering albedo and the Ångström absorption coefficient (Pokhrel et al., 2016). The RI retrievals were performed using the SMPS size distributions, as the LAS data were often not available. Therefore, this analysis is also a function of how well the SMPS size distributions characterize the aerosol geometric diameter. Figure S6 shows the retrieved wavelength-dependent RI for each fire across the entire 360-720 nm wavelength range. To demonstrate the effectiveness of the retrieval method, we report the $\chi^{2}$ of the RI retrieval in Fig. 7 at a single wavelength, $475 \mathrm{~nm}$, where the BBCES instrument had high mirror reflectivity and therefore good precision. The reported $\chi^{2}$ for each fire is from a single set of measurements through the bypass channel, approximately $1 \mathrm{~h}$ after the fire start, and therefore represents well-mixed smoke. The derived real part of the RI for the low-BC fires ranged from 1.54 to 1.69 at $475 \mathrm{~nm}$ with an average value of $1.635 \pm 0.056$, and the imaginary part ranged from $0.00 i$ to $0.23 i$ with an average value of $0.06 i \pm 0.12$. At $365 \mathrm{~nm}$, the average value of the real part was $1.605 \pm 0.041$ and the imaginary part was $0.038 i \pm 0.074$. We note that the average $k$ value is slightly greater at $475 \mathrm{~nm}$ than at $365 \mathrm{~nm}$, but the two values are consistent within the error bars of the averaged measurements of aerosol from different fuel types and fire conditions. 
Figure 7 shows a correlation between the relative fraction of $\mathrm{BC}$ in the total aerosol mass and the quality of the RI retrieval assuming Mie theory and spherical particles wellcharacterized by the SMPS. Fire B has the highest relative $\mathrm{BC}$ fraction, defined here as 1 , and is poorly described by Mie theory, with a $\chi^{2}$ of 1.3. This finding is consistent with Smith and Grainger (2014), who found that there is no refractive index that suitably describes fractal $\mathrm{BC}$ if those particles are treated as spheres with Mie theory. Fire A has a lower relative $\mathrm{BC}$ fraction and is better described by Mie theory, consistent with Sect. 4.5 and 4.6. Most of the other 11 fires analyzed here have a smaller BC fraction than Fire A and a correspondingly lower $\chi^{2}$ value. This indicates that the majority of smoke sampled during FIREX had relatively low BC and could reasonably be analyzed using Mie theory. However, we note that this freshly emitted smoke was from small-scale burns under controlled conditions and may not represent the full range of smoke aerosol types in ambient aerosol, including dust and biological fragments. Additionally, further downwind of the fire, coagulation and fractal aggregate collapse can alter the particle morphology. Furthermore, the poor fit quality of the high-BC fire (Fire B) shows that Mie theory is not appropriate for all smoke, especially smoke with a high BC fraction. Since BC fraction is not a metric that is easily quantified with remote sensing, further work is still needed to link this parameterization to remotesensing measurements to predict when Mie theory representation of wildfire smoke is appropriate.

\section{Summary and conclusions}

This paper describes the development of a new broadband cavity-enhanced spectrometer that derives the RI of biomass burning aerosol with low BC content over a very broadband wavelength region in the ultraviolet and visible spectral regions. It was outfitted with an automated flow system for size-selected retrievals of the complex refractive index of biomass burning aerosol. After measuring the $\mathrm{CO}_{2}$ Rayleigh scattering cross section across the $360-720 \mathrm{~nm}$ spectral region and confirming the long-term stability and accuracy of the instrument with repeated additions of $\mathrm{NO}_{2}$, we demonstrated the effectiveness of the RI retrieval algorithm on two laboratory standard aerosols: PSL and ammonium sulfate. Good agreement was found for each standard with other literature values. We demonstrate that the OPC is an effective method for quantifying the size distribution of the generated aerosol but that it is quite sensitive itself to the aerosol refractive index. We also demonstrate that with a simple diameter threshold cutoff to remove artifacts, the SMPS can provide accurate size distributions for spherical particles which yield retrievals consistent with literature values.

This instrument was deployed to the Missoula Fire Sciences Laboratory for the 2016 FIREX campaign, where it measured real biomass burning aerosol from a series of con- trolled burns of North American fuels. We presented measured extinction cross sections from two representative fires: lodgepole pine, which produced smoke dominated by $\mathrm{BrC}$, and sage, which produced smoke dominated by BC. The optical properties of the $\mathrm{BrC}$-dominated smoke could be modeled with Mie theory and a wavelength-dependent RI that increased its absorption component as wavelength decreases. This behavior is consistent with other observations of $\mathrm{BrC}$ and demonstrates that this BBCES instrument and retrieval algorithm is capable of measuring biomass burning aerosol.

The BC-dominated smoke, on the other hand, could not be modeled using Mie theory and was better represented by Rayleigh-Debye-Gans theory. Two possible RDG parameterizations were assessed to quantify their ability to reproduce the observations. We found that the measurement lay somewhere between the two parameterizations. Due to the large number of unknown variables and the absence of a reliable metric of the particle morphology, we do not attempt to further characterize the optical properties of this BC smoke. However, we find that a reasonable parameterization of RDG theory can largely reproduce the measured results and recommend this parameterization for further characterization of BC-dominated fires.

We retrieved RIs for 11 additional fires and found a correlation between the quality of the RI retrieval fit and the fraction of $\mathrm{BC}$, with high-BC fires, such as Fire $\mathrm{B}$, poorly described by Mie theory and those with lower BC content better described by Mie theory. We found that the majority of smoke measurements had fairly low BC content, and the RIs could therefore be reasonably retrieved. However, remotesensing retrievals of biomass burning aerosol must account for the optical properties of smoke with varying amounts of $\mathrm{BC}$, and Mie theory is therefore not always an appropriate theory to use.

Data availability. All data are available upon request to the corresponding author (caroline.womack@noaa.gov).

Supplement. The supplement related to this article is available online at: https://doi.org/10.5194/acp-21-7235-2021-supplement.

Author contributions. CCW, KMM, NLW, GA, AF, KDL, AMM, JPS, and RAW collected and analyzed the Fire Sciences Laboratory data. CAB advised the data collection of the laboratory standards and provided instrumentation. CCW, SSB, and RAW conceptualized the experiment, data collection, and data analysis. CCW wrote the data analysis code. KMM advised the data analysis. $\mathrm{CCW}$ and RAW wrote the paper with contributions from all authors.

Competing interests. The authors declare that they have no conflict of interest. 
Acknowledgements. We thank Yinon Rudich and Quanfu He for high-finesse cavity mirrors and technical discussions about their properties. We thank Agnieszka Kupc and Karl Froyd for the loan of the LAS and providing calibration information. We thank Jim Roberts, Carsten Warneke, and Bob Yokelson for coordinating the Fire Sciences Laboratory campaign and the Fire Sciences Laboratory in Missoula for hosting the campaign.

Financial support. This project was supported by the NOAA Atmospheric Chemistry, Carbon, and Climate Program (AC4); the NASA Radiation Sciences Program; and the NOAA Cooperative Agreement with CIRES (grant no. NA17OAR4320101).

Review statement. This paper was edited by Manvendra K. Dubey and reviewed by two anonymous referees.

\section{References}

Abo Riziq, A., Erlick, C., Dinar, E., and Rudich, Y.: Optical properties of absorbing and non-absorbing aerosols retrieved by cavity ring down (CRD) spectroscopy, Atmos. Chem. Phys., 7, 15231536, https://doi.org/10.5194/acp-7-1523-2007, 2007.

Adler, G., Wagner, N. L., Lamb, K. D., Manfred, K. M., Schwarz, J. P., Franchin, A., Middlebrook, A. M., Washenfelder, R. A., Womack, C. C., Yokelson, R. J., and Murphy, D. M.: Evidence in biomass burning smoke for a light-absorbing aerosol with properties intermediate between brown and black carbon, Aerosol Sci. Tech., 53, 976-989, https://doi.org/10.1080/02786826.2019.1617832, 2019.

Attwood, A. R., Washenfelder, R. A., Brock, C. A., Hu, W., Baumann, K., Campuzano-Jost, P., Day, D. A., Edgerton, E. S., Murphy, D. M., Palm, B. B., McComiskey, A., Wagner, N. L., de Sá, S. S., Ortega, A., Martin, S. T., Jimenez, J. L., and Brown, S. S.: Trends in sulfate and organic aerosol mass in the Southeast U.S.: Impact on aerosol optical depth and radiative forcing, Geophys. Res. Lett., 41, 7701-7709, https://doi.org/10.1002/2014gl061669, 2014.

Bahreini, R., Dunlea, E. J., Matthew, B. M., Simons, C., Docherty, K. S., DeCarlo, P. F., Jimenez, J. L., Brock, C. A., and Middlebrook, A. M.: Design and operation of a pressure-controlled inlet for airborne sampling with an aerodynamic aerosol lens, Aerosol Sci. Tech., 42, 465-471, https://doi.org/10.1080/02786820802178514, 2008.

Bahreini, R., Ervens, B., Middlebrook, A. M., Warneke, C., de Gouw, J. A., DeCarlo, P. F., Jimenez, J. L., Brock, C. A., Neuman, J. A., Ryerson, T. B., Stark, H., Atlas, E., Brioude, J., Fried, A., Holloway, J. S., Peischl, J., Richter, D., Walega, J., Weibring, P., Wollny, A. G., and Fehsenfeld, F. C.: Organic aerosol formation in urban and industrial plumes near Houston and Dallas, Texas, J. Geophys. Res.-Atmos., 114, D00F16, https://doi.org/10.1029/2008jd011493, 2009.

Bluvshtein, N., Flores, J. M., Riziq, A. A., and Rudich, Y.: An approach for faster retrieval of aerosols' complex refractive index using cavity ring-down spectroscopy, Aerosol Sci. Tech., 46, 1140-1150, https://doi.org/10.1080/02786826.2012.700141, 2012.
Bluvshtein, N., Lin, P., Flores, J. M., Segev, L., Mazar, Y., Tas, E., Snider, G., Weagle, C., Brown, S. S., Laskin, A., and Rudich, Y.: Broadband optical properties of biomass-burning aerosol and identification of brown carbon chromophores, J. Geophys. Res.Atmos., 122, 5441-5456, https://doi.org/10.1002/2016jd026230, 2017.

Bohren, C. F. and Huffman, D. R.: Absorption and scattering of light by small particles, Wiley-Interscience, New York, USA, 1983.

Bond, T. C. and Bergstrom, R. W.: Light absorption by carbonaceous particles: An investigative review, Aerosol Sci. Tech., 40, 27-67, https://doi.org/10.1080/02786820500421521, 2006.

Bond, T. C., Doherty, S. J., Fahey, D. W., Forster, P. M., Berntsen, T., DeAngelo, B. J., Flanner, M. G., Ghan, S., Kärcher, B., Koch, D., Kinne, S., Kondo, Y., Quinn, P. K., Sarofim, M. C., Schultz, M. G., Schulz, M., Venkataraman, C., Zhang, H., Zhang, S., Bellouin, N., Guttikunda, S. K., Hopke, P. K., Jacobson, M. Z., Kaiser, J. W., Klimont, Z., Lohmann, U., Schwarz, J. P., Shindell, D., Storelvmo, T., Warren, S. G., and Zender, C. S.: Bounding the role of black carbon in the climate system: A scientific assessment, J. Geophys. Res.-Atmos., 118, 5380-5552, https://doi.org/10.1002/jgrd.50171, 2013.

Boucher, O., Randall, D., Artaxo, P., Bretherton, C., Feingold, G., Forster, P., Kerminen, V.-M., Kondo, Y., Liao, H., Lohmann, U., Rasch, P., Satheesh, S. K., Sherwood, S., Stevens, B., and Zhang, X. Y.: Clouds and Aerosols, in: Climate Change 2013: The Physical Science Basis, Contribution of Working Group I to the Fifth Assessment Report of the Intergovernmental Panel on Climate Change, edited by: Stocker, T. F., Qin, D., Plattner, G.-K., Tignor, M., Allen, S. K., Boschung, J., Nauels, A., Xia, Y., Bex, V., and Midgley, P. M., Cambridge University Press, Cambridge, United Kingdom and New York, USA, 2013.

Chakrabarty, R. K., Moosmüller, H., Garro, M. A., Arnott, W. P., Walker, J., Susott, R. A., Babbitt, R. E., Wold, C. E., Lincoln, E. N., and Hao, W. M.: Emissions from the laboratory combustion of wildland fuels: Particle morphology and size, J. Geophys. Res.-Atmos., 111, D07204, https://doi.org/10.1029/2005jd006659, 2006.

Chakrabarty, R. K., Moosmüller, H., Chen, L.-W. A., Lewis, K., Arnott, W. P., Mazzoleni, C., Dubey, M. K., Wold, C. E., Hao, W. M., and Kreidenweis, S. M.: Brown carbon in tar balls from smoldering biomass combustion, Atmos. Chem. Phys., 10, 63636370, https://doi.org/10.5194/acp-10-6363-2010, 2010.

Chilton, J. E., Timko, R. J., and Chuhta, E. J.: Nitrogen dioxide calibration standards for portable monitors, Information Circular 9482, National Institute for Occupational Safety and Health, Department of Health and Human Services Pittsburgh Research Laboratory Pittsburg, PA, USA, 2005.

China, S., Mazzoleni, C., Gorkowski, K., Aiken, A. C., and Dubey, M. K.: Morphology and mixing state of individual freshly emitted wildfire carbonaceous particles, Nat. Commun., 4, 2122, https://doi.org/10.1038/ncomms3122, 2013.

Dennison, P. E., Brewer, S. C., Arnold, J. D., and Moritz, M. A.: Large wildfire trends in the western United States, 1984-2011, Geophys. Res. Lett., 41, 2928-2933, https://doi.org/10.1002/2014g1059576, 2014.

Dinar, E., Abo Riziq, A., Spindler, C., Erlick, C., Kiss, G., and Rudich, Y.: The complex refractive index of atmospheric and model humic-like substances (HULIS) retrieved by a cavity ring 
down aerosol spectrometer (CRD-AS), Faraday Discuss., 137, 279-295, https://doi.org/10.1039/B703111D, 2008.

Farias, T. L., Köylü, Ü. Ö., and Carvalho, M. G.: Range of validity of the Rayleigh-Debye-Gans theory for optics of fractal aggregates, Appl. Optics, 35, 6560-6567, https://doi.org/10.1364/AO.35.006560, 1996.

Fiedler, S. E., Hese, A., and Ruth, A. A.: Incoherent broad-band cavity-enhanced absorption spectroscopy, Chem. Phys. Lett., 371, 284-294, https://doi.org/10.1016/s0009-2614(03)00263-x, 2003.

Flores, J. M., Washenfelder, R. A., Adler, G., Lee, H. J., Segev, L., Laskin, J., Laskin, A., Nizkorodov, S. A., Brown, S. S., and Rudich, Y.: Complex refractive indices in the near-ultraviolet spectral region of biogenic secondary organic aerosol aged with ammonia, Phys. Chem. Chem. Phys., 16, 10629-10642, https://doi.org/10.1039/c4cp01009d, 2014a.

Flores, J. M., Zhao, D. F., Segev, L., Schlag, P., KiendlerScharr, A., Fuchs, H., Watne, ̊. K., Bluvshtein, N., Mentel, Th. F., Hallquist, M., and Rudich, Y.: Evolution of the complex refractive index in the UV spectral region in ageing secondary organic aerosol, Atmos. Chem. Phys., 14, 5793-5806, https://doi.org/10.5194/acp-14-5793-2014, 2014b.

Forrest, S. R. and Witten, T. A.: Long-range correlations in smoke-particle aggregates, J. Phys. A-Math. Gen., 12, 109-117, https://doi.org/10.1088/0305-4470/12/5/008, 1979.

Fuchs, H., Dubé, W. P., Lerner, B. M., Wagner, N. L., Williams, E. J., and Brown, S. S.: A sensitive and versatile detector for atmospheric $\mathrm{NO}_{2}$ and $\mathrm{NO}_{x}$ based on blue diode laser cavity ring-down spectroscopy, Environ. Sci. Technol., 43, 7831-7836, https://doi.org/10.1021/es902067h, 2009.

Garvey, D. M. and Pinnick, R. G.: Response characteristics of the particle measuring systems active scattering aerosol spectrometer probe (ASASP-X), Aerosol Sci. Tech., 2, 477-488, https://doi.org/10.1080/02786828308958651, 1983.

Greenblatt, G. D., Orlando, J. J., Burkholder, J. B., and Ravishankara, A. R.: Absorption measurements of oxygen between 330 and $1140 \mathrm{~nm}$, J. Geophys. Res.-Atmos., 95, 18577-18582, https://doi.org/10.1029/JD095iD11p18577, 1990.

He, Q., Bluvshtein, N., Segev, L., Meidan, D., Flores, J. M., Brown, S. S., Brune, W., and Rudich, Y.: Evolution of the complex refractive index of secondary organic aerosols during atmospheric aging, Environ. Sci. Technol., 52, 3456-3465, https://doi.org/10.1021/acs.est.7b05742, 2018.

Hermans, C.: Measurement of absorption cross sections and spectroscopic molecular parameters, http://spectrolab.aeronomie.be/ o2.htm (last access: 26 October 2020), 2011.

Huffman, J. A., Ziemann, P. J., Jayne, J. T., Worsnop, D. R., and Jimenez, J. L.: Development and characterization of a fast-stepping/scanning thermodenuder for chemically-resolved aerosol volatility measurements, Aerosol Sci. Tech., 42, 395407, https://doi.org/10.1080/02786820802104981, 2008.

Islam, M., Ciaffoni, L., Hancock, G., and Ritchie, G. A. D.: Demonstration of a novel laser-driven light source for broadband spectroscopy between $170 \mathrm{~nm}$ and $2.1 \mu \mathrm{m}$, Analyst, 138, 4741-4745, https://doi.org/10.1039/C3AN01020A, 2013.

Knutson, E. O. and Whitby, K. T.: Aerosol classification by electric mobility: apparatus, theory, and applications, J. Aerosol Sci., 6, 443-451, https://doi.org/10.1016/0021-8502(75)90060-9, 1975.
Kondo, Y., Sahu, L., Moteki, N., Khan, F., Takegawa, N., Liu, X., Koike, M., and Miyakawa, T.: Consistency and traceability of black carbon measurements made by laser-induced incandescence, thermal-optical transmittance, and filter-based photo-absorption techniques, Aerosol Sci. Tech., 45, 295-312, https://doi.org/10.1080/02786826.2010.533215, 2011.

Kupc, A., Williamson, C., Wagner, N. L., Richardson, M., and Brock, C. A.: Modification, calibration, and performance of the Ultra-High Sensitivity Aerosol Spectrometer for particle size distribution and volatility measurements during the Atmospheric Tomography Mission (ATom) airborne campaign, Atmos. Meas. Tech., 11, 369-383, https://doi.org/10.5194/amt-11-369-2018, 2018.

Lamarque, J.-F., Emmons, L. K., Hess, P. G., Kinnison, D. E., Tilmes, S., Vitt, F., Heald, C. L., Holland, E. A., Lauritzen, P. H., Neu, J., Orlando, J. J., Rasch, P. J., and Tyndall, G. K.: CAM-chem: description and evaluation of interactive atmospheric chemistry in the Community Earth System Model, Geosci. Model Dev., 5, 369-411, https://doi.org/10.5194/gmd-5369-2012, 2012.

Laskin, A., Laskin, J., and Nizkorodov, S. A.: Chemistry of atmospheric brown carbon, Chem. Rev., 115, 4335-4382, https://doi.org/10.1021/cr5006167, 2015.

Levy, R. C., Remer, L. A., and Dubovik, O.: Global aerosol optical properties and application to Moderate Resolution Imaging Spectroradiometer aerosol retrieval over land, J. Geophys. Res.Atmos., 112, D13210, https://doi.org/10.1029/2006jd007815, 2007.

Li, C., He, Q., Hettiyadura, A. P. S., Käfer, U., Shmul, G., Meidan, D., Zimmermann, R., Brown, S. S., George, C., Laskin, A., and Rudich, Y.: Formation of secondary brown carbon in biomass burning aerosol proxies through $\mathrm{NO}_{3}$ radical reactions, Environ. Sci. Technol., 54, 1395-1405, https://doi.org/10.1021/acs.est.9b05641, 2020.

Li, J., Pósfai, M., Hobbs, P. V., and Buseck, P. R.: Individual aerosol particles from biomass burning in southern Africa: 2. Compositions and aging of inorganic particles, J. Geophys. Res.-Atmos., 108, SAF 20, https://doi.org/10.1029/2002jd002310, 2003.

Liao, H., Adams, P. J., Chung, S. H., Seinfeld, J. H., Mickley, L. J., and Jacob, D. J.: Interactions between tropospheric chemistry and aerosols in a unified general circulation model, J. Geophys. Res.-Atmos., 108, 4001, https://doi.org/10.1029/2001jd001260, 2003.

Manfred, K. M., Washenfelder, R. A., Wagner, N. L., Adler, G., Erdesz, F., Womack, C. C., Lamb, K. D., Schwarz, J. P., Franchin, A., Selimovic, V., Yokelson, R. J., and Murphy, D. M.: Investigating biomass burning aerosol morphology using a laser imaging nephelometer, Atmos. Chem. Phys., 18, 1879-1894, https://doi.org/10.5194/acp-18-1879-2018, 2018.

Markowski, G. R.: Improving Twomey's algorithm for inversion of aerosol measurement data, Aerosol Sci. Tech., 7, 127-141, https://doi.org/10.1080/02786828708959153, 1987.

McMeeking, G. R., Kreidenweis, S. M., Baker, S., Carrico, C. M., Chow, J. C., Collett Jr., J. L., Hao, W. M., Holden, A. S., Kirchstetter, T. W., Malm, W. C., Moosmüller, H., Sullivan, A. P., and Wold, C. E.: Emissions of trace gases and aerosols during the open combustion of biomass in the laboratory, J. Geophys. Res.Atmos., 114, D19210, https://doi.org/10.1029/2009jd011836, 2009. 
Miles, R. E. H., Rudić, S., Orr-Ewing, A. J., and Reid, J. P.: Measurements of the wavelength dependent extinction of aerosols by cavity ring down spectroscopy, Phys. Chem. Chem. Phys., 12, 3914-3920, https://doi.org/10.1039/B923758E, 2010.

Min, K.-E., Washenfelder, R. A., Dubé, W. P., Langford, A. O., Edwards, P. M., Zarzana, K. J., Stutz, J., Lu, K., Rohrer, F., Zhang, Y., and Brown, S. S.: A broadband cavity enhanced absorption spectrometer for aircraft measurements of glyoxal, methylglyoxal, nitrous acid, nitrogen dioxide, and water vapor, Atmos. Meas. Tech., 9, 423-440, https://doi.org/10.5194/amt-9423-2016, 2016.

Moise, T., Flores, J. M., and Rudich, Y.: Optical properties of secondary organic aerosols and their changes by chemical processes, Chem. Rev., 115, 4400-4439, https://doi.org/10.1021/cr5005259, 2015.

Moosmüller, H. and Arnott, W. P.: Particle optics in the rayleigh regime, J. Air Waste Manage., 59, 1028-1031, https://doi.org/10.3155/1047-3289.59.9.1028, 2009.

Moosmüller, H., Chakrabarty, R. K., and Arnott, W. P.: Aerosol light absorption and its measurement: A review, J. Quant. Spectrosc. Ra., 110, 844-878, https://doi.org/10.1016/j.jqsrt.2009.02.035, 2009.

Nakayama, T., Matsumi, Y., Sato, K., Imamura, T., Yamazaki, A., and Uchiyama, A.: Laboratory studies on optical properties of secondary organic aerosols generated during the photooxidation of toluene and the ozonolysis of $\alpha$-pinene, J. Geophys. Res.Atmos., 115, D24204, https://doi.org/10.1029/2010jd014387, 2010.

Nikolov, I. D. and Ivanov, C. D.: Optical plastic refractive measurements in the visible and the near-infrared regions, Appl. Optics, 39, 2067-2070, https://doi.org/10.1364/AO.39.002067, 2000.

Omar, A. H., Winker, D. M., Vaughan, M. A., Hu, Y., Trepte, C. R., Ferrare, R. A., Lee, K.-P., Hostetler, C. A., Kittaka, C., Rogers, R. R., Kuehn, R. E., and Liu, Z.: The CALIPSO automated aerosol classification and lidar ratio selection algorithm, J. Atmos. Ocean. Tech., 26, 1994-2014, https://doi.org/10.1175/2009jtecha1231.1, 2009.

Pan, X., Ichoku, C., Chin, M., Bian, H., Darmenov, A., Colarco, P., Ellison, L., Kucsera, T., da Silva, A., Wang, J., Oda, T., and Cui, G.: Six global biomass burning emission datasets: intercomparison and application in one global aerosol model, Atmos. Chem. Phys., 20, 969-994, https://doi.org/10.5194/acp-20-9692020, 2020.

Platt, U., Meinen, J., Pöhler, D., and Leisner, T.: Broadband Cavity Enhanced Differential Optical Absorption Spectroscopy (CEDOAS) - applicability and corrections, Atmos. Meas. Tech., 2, 713-723, https://doi.org/10.5194/amt-2-713-2009, 2009.

Pokhrel, R. P., Wagner, N. L., Langridge, J. M., Lack, D. A., Jayarathne, T., Stone, E. A., Stockwell, C. E., Yokelson, R. J., and Murphy, S. M.: Parameterization of single-scattering albedo (SSA) and absorption Ångström exponent (AAE) with EC/OC for aerosol emissions from biomass burning, Atmos. Chem. Phys., 16, 9549-9561, https://doi.org/10.5194/acp-169549-2016, 2016.

Pósfai, M., Simonics, R., Li, J., Hobbs, P. V., and Buseck, P. R.: Individual aerosol particles from biomass burning in southern Africa: 1. Compositions and size distributions of carbonaceous particles, J. Geophys. Res.-Atmos., 108, SAF 19, https://doi.org/10.1029/2002jd002291, 2003.
Schwarz, J. P., Gao, R. S., Fahey, D. W., Thomson, D. S., Watts, L. A., Wilson, J. C., Reeves, J. M., Darbeheshti, M., Baumgardner, D. G., Kok, G. L., Chung, S. H., Schulz, M., Hendricks, J., Lauer, A., Kärcher, B., Slowik, J. G., Rosenlof, K. H., Thompson, T. L., Langford, A. O., Loewenstein, M., and Aikin, K. C.: Single-particle measurements of midlatitude black carbon and light-scattering aerosols from the boundary layer to the lower stratosphere, J. Geophys. Res.-Atmos., 111, D16207, https://doi.org/10.1029/2006jd007076, 2006.

Schwarz, J. P., Spackman, J. R., Fahey, D. W., Gao, R. S., Lohmann, U., Stier, P., Watts, L. A., Thomson, D. S., Lack, D. A., Pfister, L., Mahoney, M. J., Baumgardner, D., Wilson, J. C., and Reeves, J. M.: Coatings and their enhancement of black carbon light absorption in the tropical atmosphere, J. Geophys. Res.-Atmos., 113, D03203, https://doi.org/10.1029/2007jd009042, 2008.

Selimovic, V., Yokelson, R. J., Warneke, C., Roberts, J. M., de Gouw, J., Reardon, J., and Griffith, D. W. T.: Aerosol optical properties and trace gas emissions by PAX and OP-FTIR for laboratory-simulated western US wildfires during FIREX, Atmos. Chem. Phys., 18, 2929-2948, https://doi.org/10.5194/acp18-2929-2018, 2018.

Shardanand, and Rao, A. D. P.: Absolute Rayleigh scattering cross sections of gases and freons of stratospheric interest in the visible and ultraviolet regions, Technical Note D-8442, NASA Wallops Flight Center in Wallops Island, VA, USA, 1977.

Smith, A. J. A. and Grainger, R. G.: Simplifying the calculation of light scattering properties for black carbon fractal aggregates, Atmos. Chem. Phys., 14, 7825-7836, https://doi.org/10.5194/acp14-7825-2014, 2014.

Sneep, M. and Ubachs, W.: Direct measurement of the Rayleigh scattering cross section in various gases, J. Quant. Spectrosc. Ra., 92, 293-310, https://doi.org/10.1016/j.jqsrt.2004.07.025, 2005.

Sorensen, C. M.: Light scattering by fractal aggregates: A review, Aerosol Sci. Tech., 35, 648-687, https://doi.org/10.1080/02786820117868, 2001.

Stockwell, C. E., Yokelson, R. J., Kreidenweis, S. M., Robinson, A. L., DeMott, P. J., Sullivan, R. C., Reardon, J., Ryan, K. C., Griffith, D. W. T., and Stevens, L.: Trace gas emissions from combustion of peat, crop residue, domestic biofuels, grasses, and other fuels: configuration and Fourier transform infrared (FTIR) component of the fourth Fire Lab at Missoula Experiment (FLAME-4), Atmos. Chem. Phys., 14, 9727-9754, https://doi.org/10.5194/acp-14-9727-2014, 2014.

Szymanski, W. W., Nagy, A., and Czitrovszky, A.: Optical particle spectrometry - Problems and prospects, J. Quant. Spectrosc. Ra., 110, 918-929, https://doi.org/10.1016/j.jqsrt.2009.02.024, 2009.

Thalman, R. and Volkamer, R.: Inherent calibration of a blue LED-CE-DOAS instrument to measure iodine oxide, glyoxal, methyl glyoxal, nitrogen dioxide, water vapour and aerosol extinction in open cavity mode, Atmos. Meas. Tech., 3, 1797-1814, https://doi.org/10.5194/amt-3-1797-2010, 2010.

Twomey, S.: Comparison of constrained linear inversion and an iterative nonlinear algorithm applied to the indirect estimation of particle size distributions, J. Comput. Phys., 18, 188-200, https://doi.org/10.1016/0021-9991(75)90028-5, 1975.

Vandaele, A. C., Hermans, C., Simon, P. C., Carleer, M., Colin, R., Fally, S., Mérienne, M. F., Jenouvrier, A., and Coquart, B.: Measurements of the $\mathrm{NO}_{2}$ absorption crosssection from $42000 \mathrm{~cm}^{-1}$ to $10000 \mathrm{~cm}^{-1}(238-1000 \mathrm{~nm})$ 
at 220 and $294 \mathrm{~K}$, J. Quant. Spectrosc. Ra., 59, 171-184, https://doi.org/10.1016/S0022-4073(97)00168-4, 1998.

Varma, R. M., Ball, S. M., Brauers, T., Dorn, H.-P., Heitmann, U., Jones, R. L., Platt, U., Pöhler, D., Ruth, A. A., Shillings, A. J. L., Thieser, J., Wahner, A., and Venables, D. S.: Light extinction by secondary organic aerosol: an intercomparison of three broadband cavity spectrometers, Atmos. Meas. Tech., 6, 3115-3130, https://doi.org/10.5194/amt-6-3115-2013, 2013.

von der Weiden, S.-L., Drewnick, F., and Borrmann, S.: Particle Loss Calculator - a new software tool for the assessment of the performance of aerosol inlet systems, Atmos. Meas. Tech., 2, 479-494, https://doi.org/10.5194/amt-2-479-2009, 2009.

Washenfelder, R. A., Langford, A. O., Fuchs, H., and Brown, S. S.: Measurement of glyoxal using an incoherent broadband cavity enhanced absorption spectrometer, Atmos. Chem. Phys., 8, 7779-7793, https://doi.org/10.5194/acp-8-7779-2008, 2008.

Washenfelder, R. A., Flores, J. M., Brock, C. A., Brown, S. S., and Rudich, Y.: Broadband measurements of aerosol extinction in the ultraviolet spectral region, Atmos. Meas. Tech., 6, 861-877, https://doi.org/10.5194/amt-6-861-2013, 2013.

Washenfelder, R. A., Attwood, A. R., Brock, C. A., Guo, H., Xu, L., Weber, R. J., Ng, N. L., Allen, H. M., Ayres, B. R., Baumann, K., Cohen, R. C., Draper, D. C., Duffey, K. C., Edgerton, E., Fry, J. L., Hu, W. W., Jimenez, J. L., Palm, B. B., Romer, P., Stone, E. A., Wooldridge, P. J., and Brown, S. S.: Biomass burning dominates brown carbon absorption in the rural southeastern United States, Geophys. Res. Lett., 42, 653-664, https://doi.org/10.1002/2014g1062444, 2015.

Washenfelder, R. A., Attwood, A. R., Flores, J. M., Zarzana, K. J., Rudich, Y., and Brown, S. S.: Broadband cavity-enhanced absorption spectroscopy in the ultraviolet spectral region for measurements of nitrogen dioxide and formaldehyde, Atmos. Meas. Tech., 9, 41-52, https://doi.org/10.5194/amt-9-41-2016, 2016.
Watson, J. G.: Visibility: Science and regulation, J. Air Waste Manage., 52, 628-713, https://doi.org/10.1080/10473289.2002.10470813, 2002.

Westerling, A. L., Hidalgo, H. G., Cayan, D. R., and Swetnam, T. W.: Warming and earlier spring increase western U.S. forest wildfire activity, Science, 313, 940-943, https://doi.org/10.1126/science.1128834, 2006.

Wiedinmyer, C., Quayle, B., Geron, C., Belote, A., McKenzie, D., Zhang, X., O'Neill, S., and Wynne, K. K.: Estimating emissions from fires in North America for air quality modeling, Atmos. Environ., 40, 3419-3432, https://doi.org/10.1016/j.atmosenv.2006.02.010, 2006.

Wiedinmyer, C., Akagi, S. K., Yokelson, R. J., Emmons, L. K., AlSaadi, J. A., Orlando, J. J., and Soja, A. J.: The Fire INventory from NCAR (FINN): a high resolution global model to estimate the emissions from open burning, Geosci. Model Dev., 4, 625641, https://doi.org/10.5194/gmd-4-625-2011, 2011.

Zhang, X., Kim, H., Parworth, C. L., Young, D. E., Zhang, Q., Metcalf, A. R., and Cappa, C. D.: Optical Properties of Wintertime Aerosols from Residential Wood Burning in Fresno, CA: Results from DISCOVER-AQ 2013, Environ. Sci. Technol., 50, 16811690, https://doi.org/10.1021/acs.est.5b04134, 2016.

Zhao, W., Xu, X., Fang, B., Zhang, Q., Qian, X., Wang, S., Liu, P., Zhang, W., Wang, Z., Liu, D., Huang, Y., Venables, D. S., and Chen, W.: Development of an incoherent broad-band cavityenhanced aerosol extinction spectrometer and its application to measurement of aerosol optical hygroscopicity, Appl. Optics, 56, 16-22, https://doi.org/10.1364/AO.56.000E16, 2017. 